January 2017

\title{
The Social Origins of Innovation Failures
}

Laura Pedraza-Farina

Northwestern University

\section{Recommended Citation}

Laura Pedraza-Farina, The Social Origins of Innovation Failures, 70 SMU L. REV. 377 (2017)

https://scholar.smu.edu/smulr/vol70/iss2/6

This Article is brought to you for free and open access by the Law Journals at SMU Scholar. It has been accepted for inclusion in SMU Law Review by an authorized administrator of SMU Scholar. For more information, please visit http://digitalrepository.smu.edu. 


\title{
The Social Origins of Innovation FAILURES
}

\author{
Laura G. Pedraza-Fariña*
}

This Article identifies and describes a crucial source of innovation failure-linked not to the market but to the structure of social relations that underlie market transactions-that this Article terms social network innovation failures. This source of innovation failure, however, has been obscured by two assumptions in traditional market failure models of innovation. First, market failure models frequently assume that public, non-secret knowledge (or information) will flow freely among communities of innovators and be put to its optimal use. Second, market failure models pay little attention to how good ideas emerge, assuming that good ideas will follow from investment in research and development.

Social network failures are failures of social interaction. Drawing on studies from the sociology of networks as well as original ethnographic research in innovator communities, this Article develops a taxonomy of social network innovation failures: (1) lack of social ties; (2) cognitive distance; and (3) different (or clashing) evaluative frames. It then illustrates how these social network innovation failures are endemic in a wide variety of fields, including computer science, mathematics, public health, and medicine, allowing key pieces of publicly available knowledge and expertise needed to solve complex problems to remain trapped in communities of innovators that do not interact with each other. Understanding social barriers to information flow is especially important in light of findings in the sociology literature that breakthrough ideas arise from the work of teams that bring together knowledge from cognitively-distant communities

* Assistant Professor of Law, Northwestern Pritzker School of Law. I have benefited greatly from comments from and conversations with Stephanie Bair, Christopher Buccafusco, Michael Burstein, Sarah Burstein, Anthony Casey, Brian Casey, Peter DiCola, Erin Delaney, Shari Seidman Diamond, Roger Ford, Michael Frakes, Brett Frischmann, Paul Heald, Erik Hovenkamp, Daniel Kelly, Dmitry Karshtedt, Joshua Kleinfeld, Michael Madison, Gregory Mandel, Mark McKenna, Andrew Michaels, Kali Murray, Lisa Larrimore Ouellette, James Pfander, Nicholson Price III, Andres Sawicki, David Schwartz, Matthew Spitzer, Katherine Strandburg, Melissa Waserman, John Whealan, Felix Wu, and Stephen Yelderman. For helpful comments, discussion, and suggestions, I thank the audiences at Northwestern University Science in Human Culture Faculty Colloquium, Junior Scholars in Intellectual Property Conference (2016), Works-in-Progress-in-Intellectual Property (2016), Loyola-Chicago-Kent IP Colloquium (2016), University of Illinois College of Law Intellectual Property Colloquium (2016), Marquette University Law School's IP Colloquium (2016), University of Oklahoma Junior Scholars Conference (2016), George Washington University Law School IP Series (2016), Junior Scholars in Intellectual Property Workshop (2017), Cardozo Law School Intellectual Property and Information Law Colloquium (2017), and the faculty at Notre Dame Law School. Trevor Martin and Christopher White provided excellent research and editing assistance. 
to find and frame new problems at their intersection. Breakthrough ideas are rare precisely because of social network failures.

Not only does patent law fail to address these social barriers to innovation, patent law, as currently designed, actually reinforces them. The assumption that public knowledge is free flowing, as well as an emphasis on problem-solving that assumes that problems to be solved are simply out there, underlie the key patent law doctrines of novelty, obviousness, and utility, often resulting in decisions that frustrate patent law's fundamental goal of incentivizing innovation. Correcting social network innovation failures requires reorienting patent doctrine to reward not only problem-solving but also problem-finding and problem-framing.

Identifying the social causes underlying innovation failures is essential to the design of effective law and policy interventions. Just as market failure analyses of innovation identified free-riding as a root cause of market inefficiencies - justifying a property right in information as the targeted curesocial network failure analyses identify the social organization and division of knowledge as an independent cause of innovation failure that calls for the design of new, targeted legal interventions. The three types of social network failures identified in this Article recommend the reorganization of innovation policy to prioritize the building of knowledge infrastructures and the restructuring of research funding from a discipline-based to a problem-based model.

\section{TABLE OF CONTENTS}

INTRODUCTION .................................. 379

I. MARKET FAILURES IN INNOVATION ............ 386

A. Assumption One: Information's Tendency to Flow Freely ................................. 389

B. Assumption Two: The Origin of IdeAs ......... 397

II. SOCIAL NETWORKS AND INNOVATION: FROM BROKERAGE TO STRUCTURAL FOLDS .......... 399

A. How Information Flows: Structural Holes and Brokerage in InNovation .................... 400

B. Where Do Good Ideas Come From? Structural Folds and Team Creativity.................. 403

C. Problem Finding and Problem Framing in Breakthrough InNOVATION ................... 406

III. SOCIAL NETWORK FAILURES IN INNOVATION: THREE CASE STUDIES ....................... 410

A. Social Network Failures in Public Health: Light Cigarettes and Cancer ................ 410

B. Social Network Failures in Mathematics/ Computer Science: The Kadison-Singer

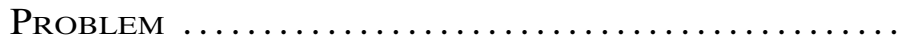

C. Social Network Failures in Medical Care: Fertility in Cancer Patients .................. 
D. A Taxonomy of Social Network Failure ....... 423

IV. Implications for Patent Law Doctrine ............... 424

A. The Free Flow Assumption in Patent Doctrine

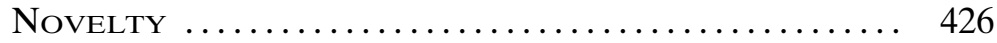

1. Obviousness .......................... 427

B. The Origin of Ideas Assumption in Patent

Doctrine.......................... 430

1. Obviousness ......................... 431

2. Utility ......................... 434

3. Comparison with Psychological Approaches ...... 435

C. Correcting Mistaken Assumptions ............. 436

V. IMPLICATIONS FOR INNOVATION THEORY . . . . . 438

A. Building Knowledge Infrastructures.......... 439

B. Building Teams with Overlapping Membership

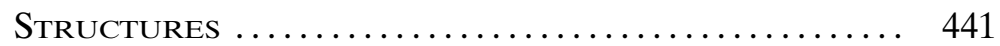

C. Emphasizing Problem-Based vs. Discipline-Based

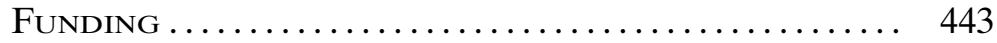

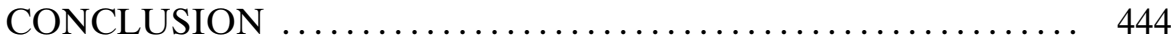

\section{LIST OF FIGURES}

Figure 1: Designing Innovation Policy to Cure Market Failures .... 388

Figure 2: Structural Holes in Information Space ............... 401

Figure 3: Brokers Occupy Structural Holes in Information Space .. 401

Figure 4: Structural Holes vs. Structural Folds ................. 406

Figure 5: A Taxonomy of Social Network Failures .............. 424

Figure 6: Designing Innovation Policy to Cure Social Network

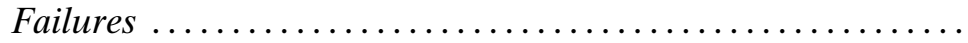

\section{INTRODUCTION}

$\mathrm{M}$

ARKET failure analyses of innovation have shaped our modern legal understanding of when and how governmental intervention is required to optimize innovation outcomes. ${ }^{1}$ Courts and agencies tasked with interpreting patent statutes understand the role of patent rights as correcting market failures. ${ }^{2}$ Legal scholars have relied on market failure analyses to both justify the need for expansive patent rights and to argue for changes in specific patent law doctrines. ${ }^{3}$ But these

1. See generally Kenneth Arrow, Economic Welfare and the Allocation of Resources for Invention, in The Rate And Direction of Inventive Activity 609 (Richard Nelson ed., 1962) (Arrow's analysis of the underproduction of information in an unregulated market has been profoundly influential in shaping the current legal debate over the contours of intellectual property and other innovation policies). See also infra Part I.

2. See infra Parts I.A, I.B, IV.B.

3. See, e.g., Herbert Hovenkamp et al., IP and Antitrust § 1.3a at 1-10 (2014) ("[A] fundamental principle of our economic system is the proposition that free market competition will best ensure an efficient allocation of resources in the absence of a market failure.”); William M. Landes \& Richard A. Posner, The Economic Structure of Intellectual Property Law 294-97 (2003); U.S. Fed. Trade Comm'n, To Promote 
analyses make important assumptions-reflected in patent law doctrine-about how new knowledge emerges and spreads across society that have remained largely unexamined. This Article identifies and challenges these assumptions. In so doing, it uncovers, describes, and characterizes a different type of innovation failure-what I term social network innovation failure - that stems from the lack of social interaction among communities with complementary knowledge or expertise. Social network innovation failures prevent the flow of information necessary to find, frame, and ultimately solve complex problems. Dismantling the assumptions underlying market failure analyses and understanding this new type of innovation failure are thus crucial steps to develop effective legal interventions to foster breakthrough innovation. This is the aim of this Article.

Traditional market failure narratives justify governmental intervention in the market for innovation as necessary to correct the underproduction of new information-the lifeblood of innovation. ${ }^{4}$ In a world without patents or other government subsidies, once an inventor discloses her invention to the public, others ("free-riders") will be able to copy the invention at a low cost-undercutting the innovator's profits and preventing her from recouping her research and development (R\&D) expenditures. ${ }^{5}$ Knowing this ex ante, innovators will both underinvest in R\&D and overinvest in secrecy. ${ }^{6}$ By granting innovators the right to exclude others from practicing their invention, patents make information appropriable-encouraging R\&D investment, research disclosure, and market transactions in information prior to commercialization. ${ }^{7}$

But hiding behind this traditional narrative are two interrelated assumptions: that information, once disclosed, will flow to those innovators who need it; ${ }^{8}$ and that new ideas will simply flow from increased R\&D

Innovation: The Proper Balance of Competition and Patent Law and Policy 5-6 (2003); Michael Abramowicz \& John F. Duffy, The Inducement Standard of Patentability, 120 Yale L. J. 1590, 1593-96 (2011); F. Scott Kieff, IP Transactions: On the Theory \& Practice of Commercializing Innovation, 42 Hous. L. REv. 727, 754 (2005) (turning to market failure analysis to design policy and legal responses to information sharing). See also infra Parts I.A, I.B.

4. See, e.g., Arrow, supra note 1, at 623. See also infra Part I.

5. See, e.g., Arrow, supra note 1, at 615; Harold Demsetz, Information and Efficiency: Another Viewpoint, 12 J. LAw \& ECON. 1, 10 (1969) ("[I]f information is to be produced privately, its producers must be able to realize revenues from the use or sale of information.”); Mark A. Lemley, Ex Ante versus Ex Post Justifications for Intellectual Property, 71 U. CHI. L. Rev. 129, 129 (2004) (describing the justification outlined here as the "standard justification for intellectual property" in the United States). See also infra Part I.

6. See, e.g., infra Part I.

7. Cf. Amy Kapczynski \& Talha Syed, The Continuum of Excludability and the Limits of Patents, 122 Yale L. Rev. 1900, 1908 (2013).

8. The origin of the "free flow of information" assumption stretches back to Thomas Jefferson, who famously compared information to "fire, expansible over all space ... incapable of confinement or exclusive appropriation." Thomas Jefferson to Isaac McPherson, (Aug. 13, 1813), in 13 The Writings of Thomas Jefferson 333-35 (Andrew A. Lipscomb \& Albert Ellery Bergh eds., 1905). This assumption continues in present-day legal analyses. See infra Part I.A. 
investment. ${ }^{9}$ What is wrong with this characterization of information as free-flowing, and with this lack of analysis into how good ideas emerge in the first place? After all, at first glance it appears indisputably true that, once information is placed in the public domain, any innovator faced with a particular problem will be able to search for and use that information, if pertinent, to solve it. And analysis into how ideas emerge may seem a fool's errand-something as intangible as an idea may appear to be inextricably linked with individual mental processes and capabilities. ${ }^{10}$ But here's what this analysis overlooks: public information and expertise needed to solve complex problems is often not meaningfully available to innovators facing those problems. It turns out that how individuals search for information, what type of information they search for and where, is strongly influenced by their membership in particular innovator communities. ${ }^{11}$ In turn, a growing literature in the sociology of networks shows that highly successful and creative ideas and products ("breakthrough innovation") emerge from the recombination and synthesis of knowledge from cognitively distant innovator communities. ${ }^{12}$

To make this point more concrete, and to illustrate how challenging the free-flow and origin of ideas assumption has important consequences for current views of innovation policy and patent law, let us consider the following example: ${ }^{13}$

In 2013, three computer scientists solved a famous mathematical problem-the Kadison-Singer problem - that had "defied the best efforts of some of the most talented mathematicians of the last 50 years." 14 The Kadison-Singer problem was formulated in 1959 by two mathematicians interested in quantum theory. ${ }^{15}$ It asks: can scientists extrapolate unique information about a quantum system from a scenario in which not all features can be observed or measured ${ }^{16}$ At its core, the Kadison-Singer problem deals with the ability of experimental physics to uniquely measure and describe reality. For the first two decades of its existence, and despite its publication in mathematical journals, the Kadison-Singer problem remained the province of the $\mathrm{C}^{*}$ algebra mathematics communityin the words of an applied mathematician-"the most abstract nonsense

9. See infra Part I.B.

10. See Jessica Silbey, The Mythical Beginnings of Intellectual Property, 15 Geo. MAsON L. REv. 319, 320, 330 (2008) (arguing that patent law is structured around a "central origin myth" that views the moment of creation as "enchanted"-and thus potentially outside analytical scrutiny-and as ... the "'heart' of what it means to be an inventor").

11. See infra Part II.A.

12. See infra Parts II.B, II.C.

13. I am indebted to Erik Hovenkamp for bringing the Kadison-Singer problem to my attention as an illustration of social network failures.

14. Peter G. Casazza \& Janet C. Tremain, Consequences of the Marcus/Spielman/ Srivastava Solution of the Kadison-Singer Problem, in New Trends in ApPlied HarMONIC AnAlysis 191, 191 (A. Aldroubi et al. eds., 2016).

15. See Erica Klarreich, Outsiders Crack 50-Year-Old Math Problem, QuAnta Mag., Nov. 24, 2015, at 2.

16. See Nikhil Srivastava, The Solution of the Kadison-Singer Problem, Video Tutorial, https://www.youtube.com/watch?v=lnRHuuMjKrQ [https://perma.cc/UD88-CKNB]. 
that exists in mathematics," of which "[n]obody outside the area knows much." 17 Then, in 1979, an applied mathematician "popularized the problem" by showing that it was equivalent to a question in mainstream mathematics about whether matrices could be broken up into smaller chunks. ${ }^{18}$ Viewed under this new light, solving the Kadison-Singer problem quickly became a key undertaking in mathematics and engineeringgiving rise to multiple partial solutions, but no complete solutions. ${ }^{19}$

Finally, in 2008, a computer scientist at Yale University, Daniel Spielman, spoke with his colleague, mathematician Gil Kalai, about his current research project, which focused on how to "sparsify" a computer network "so that it has fewer connections between nodes but still preserves the essential features of the original network." 20 To mathematician Kalai, Spielman's research problem was a version of the Kadison-Singer problem-a problem Spielman had never even heard of. ${ }^{21}$ Indeed, Spielman knew nothing of $C^{*}$ algebra either. But when framed as a sparsifying problem, Spielman and his team were able to provide a solution in five years-using tools that mathematicians are still struggling to understand. ${ }^{22}$ It is misleading, however, to say that the computer scientists alone solved a problem that had stumped mathematicians. Rather, mathematicians, using their expertise, were able to provide only part of the answer to the puzzle. Computer scientists had the expertise to solve the last part. As one member of Spielman's team put it: "I think the reason why this problem lasted 50 years is because it really had two parts that were hard." 23 In other words, solving it required the collective expertise of two communities (mathematics and computer science) that rarely interacted with each other. ${ }^{24}$

What does this example illustrate? First, rather than being free flowing, public knowledge is often not in fact meaningfully accessible to innovators faced with a particular problem because of reasons related to the social organization of knowledge-making. Modern knowledge-making is organized in very specialized, small subfields that often do not communicate with each other and, as a consequence, are not aware (or cannot interpret) each other's research questions, findings, and ways of framing those questions. Thus, despite being nominally public, knowledge about the Kadison-Singer problem remained trapped within the $\mathrm{C}^{*}$ algebra community for two decades and within the mathematics, applied mathematics, and engineering communities for the following thirty years. Importantly, knowledge about the Kadison-Singer problem traveled through person-to-person interactions-notably those between Kalai and

17. Klarreich, supra note 15 , at 3 .

18. Klarreich, supra note 15.

19. See, e.g., Klarreich, supra note 15, at 1; Dana Mackenzie, Kadison-Singer Problem Solved, 47 SIAM News (2014).

20. Klarreich, supra note 15 , at 1 .

21. Klarreich, supra note 15 , at 1 .

22. Klarreich, supra note 15 , at 1.

23 . Klarreich, supra note 15 , at 6 .

24. See infra Part III.B. 
Spielman - not through reading publicly available knowledge. Second, solving complex problems often requires the combination of multiple expertises that reside in non-interacting communities. In the example above, solving the Kadison-Singer problem required interaction between mathematicians and computer scientists. Such interaction facilitated the translation, or re-framing, of the problem from $\mathrm{C}^{*}$ algebra language to that of computer science and allowed computer scientists to use their tools to finally reach a complete solution to the problem. Indeed, since solving the Kadison-Singer problem, mathematicians have held several workshops to create teams that unite the disparate fields of $\mathrm{C}^{*}$ algebra and computer science. ${ }^{25}$

This last point-the need for teams that combine multiple subspecialties and multiple types of expertises to solve complex problems-brings us back to the second assumption in market failure analyses of innovation: assumption that good ideas will simply arise from investment in research and development. In contrast, a rich body of work in the sociology of networks and the sociology of science has long been preoccupied with understanding both how knowledge travels and how good ideas emerge. ${ }^{26}$ That work has provided mounting empirical evidence that a crucial step in idea generation-but one that is underappreciated in both patent law doctrine and theory - is problem finding and problem framing. ${ }^{27}$ Once a problem is sharply defined, the steps to its solution frequently reveal themselves. ${ }^{28}$ Viewed in this way, to think about innovation as beginning with a pre-existing problem and ending with product development is to overlook the most important steps that lead to idea-generation: finding and framing the problem that a particular idea is attempting to solve. In turn, "generating new problems, new knowledge and new capabilities (as opposed to transferring already accepted ideas)" 29 requires deep and frequent interaction between cognitively-distant communities..$^{30}$

The solution of the Kadison-Singer problem is a powerful illustration of this point: its solution required recognizing that the "sparsifying" problem facing computer scientists was the same as the "linear algebra matrices" problem in the several mathematics subcommunities-an example of problem-framing. ${ }^{31}$ Nevertheless, as the history of the Kadison-Singer problem also shows, the social division of knowledge in non-interacting communities of innovators hampers meaningful information flow between cognitively distant communities, in turn delaying problem-finding and problem-framing.

The Kadison-Singer problem and its solution involve abstract mathe-

25. See infra Part III.B.

26. See infra Part II.

27. See infra Parts II.B, II.C.

28. Infra Parts II.B, II.C.

29. Balazs Vedres \& David Stark, Structural Folds: Generative Disruption in Overlapping Groups, 115 Ам. J. Soc. 1150, 1158 (2010).

30. Id. See also case studies infra Part III.

31. See Srivastava, supra note 16. 
matics of the type that is not the subject of patent protection..$^{32}$ Nevertheless, the basic dynamics of knowledge-making and organization in innovator communities illustrated by this example, as I show in Parts II and III, is reproduced in more applied fields that lead to patentable innovations. Indeed, recognizing social network innovation failures has important implications for patent law doctrine and theory, as well as for innovation law and theory more broadly.

Perhaps unsurprisingly, given the influence of market failure models in the development of patent law doctrine and theory, the important legal doctrines of novelty, obviousness, and utility also reflect these twin assumptions. Specifically, relying on market failure models of innovation, courts have systematically widened the amount of information (or prior art) that is considered accessible to a person having ordinary skill in the art. ${ }^{33}$ While advances in information technology justify casting an increasingly wider net over the amount and types of information available to innovators, persistent social barriers effectively limit the availability of some types of information. Yet, the key doctrinal test that is meant to cabin the reach of prior art-the analogous art doctrine-lacks a principled way to distinguish between accessible and inaccessible prior art. And just as market failure analyses of innovation pay little attention to the origin of good ideas, so does patent law, through its utility and obviousness doctrines, often assume that problems to be solved are simply out there. ${ }^{34}$ This stylized view of what constitutes prior art, and the focus on problem-solving to the exclusion of problem-finding and framing, is out of sync with real world research. And it can have the unintended consequence of discouraging the very type of boundary-crossing teamwork that leads to breakthrough discoveries.

These assumptions feature prominently in recent cases such as Apple $v$. Samsung. ${ }^{35}$ Two key questions in Apple were whether Apple's "slide to unlock" patent that solved a "pocket dialing" problem was an obvious extension of touchscreen technology for home security systems, and how to define the relevant field of endeavor. ${ }^{36}$ When faced with conflicting versions of what constitutes a field of endeavor, or how to conceptualize the "problem to be solved," 37 the Federal Circuit and the Supreme Court have often relied on "common sense" to effectively come up with their own way of framing the problems facing innovators. ${ }^{38}$ But in Apple, un-

32. See Alice Corp. Pty., Ltd. v. CLS Bank Intern., 134 S. Ct. 2347, 2354 (2014).

33. See infra Part IV.A. Obviousness.

34. See infra Part IV.B. Obviousness and Utility.

35. Apple Inc. v. Samsung Elec. Co., Ltd., 816 F.3d 788 (Fed. Cir. 2016). See infra Parts I.A, IV.B (providing an in-depth analysis of the Apple v. Samsung and other relevant cases).

36. 816 F.3d at $798,802$.

37. See infra Part IV.B.

38. See, e.g., Apple v. Samsung, 816 F.3d at 809 ("Considering the 'reality of the circumstances-in other words, common sense,' a skilled artisan would have considered Xrgomics to be within the scope of the art searched.") (quoting In re Oetiker, 977 F.2d 1443, 1447 (Fed. Cir. 1992)). See also infra Part IV.B. 
derstanding that both security system and cell phone designers faced similar design problems, and framing the problem of designing a user friendly interface for home entertainment and security systems as one that applies to the problem of "pocket dialing" may, in itself, be an innovative contribution-particularly if these two communities were not in routine communication. ${ }^{39}$

Much like the solving of the Kadison-Singer problem, which required recognizing that the "sparsifying" problem facing computer scientists was the same as the "linear algebra matrices" problem in the several mathematics subcommunities, a key step in Apple's innovation may have been framing the "pocket dialing" problem as a problem addressed by home security systems. ${ }^{40}$

At a minimum, addressing social network failures requires confronting how incorrect assumptions about information flow and the origin of ideas manifest themselves in patent law doctrine and designing tools-which can involve the use of network analysis itself ${ }^{41}$ - to address them. Understanding social network failures in innovation, however, has important implications beyond identifying and correcting these misconceptions in patent doctrine. Social network failure analysis provides a new justification for governmental intervention in innovative activity, rooted in hurdles created by the social organization and division of knowledge. In turn, designing effective interventions requires both an in-depth understanding of the causes of social network failures and a comparative analysis of multiple innovation policy levers-including, in addition to patents, grants, prizes, taxes, and private mechanisms - to identify the optimal combination of incentives to mitigate them. ${ }^{42}$

The remainder of this Article proceeds as follows. Part I identifies and challenges the twin underlying assumptions in market failure models of innovation: (1) that non-secret knowledge will tend to flow freely across communities; and (2) that ideas preexist (and are exogenous to) any relevant analysis of innovation. Part II introduces the reader to the literature in the sociology of networks. This literature provides the theoretical background to challenge these two assumptions and to highlight a crucial source of innovation failure that has been overlooked by legal scholarswhat I term "social network failures in innovation." Part III develops the concept of social network failures in innovation through three case studies in public health, computer science/mathematics, and medical research. The case studies draw both from my original empirical research and from research by other network scholars. Through these case studies, I develop a taxonomy of social barriers to the flow of information and to the formation of boundary-crossing teams to address complex problems. Part IV turns from patent theory to patent doctrine. It shows how these twin as-

\footnotetext{
39. See infra Parts I.A, IV.B.

40. Infra Parts I.A, IV.B.

41. See infra Part IV.C.

42. See infra Part V.
} 
sumptions pervade patent law doctrine and proposes the redesign of utility, obviousness, and novelty law to align them with the realities of how research happens on the ground, including by deploying network analytic tools themselves to map relevant communities of practice. Part V concludes by analyzing the implications of social network failures for innovation theory and policy more broadly. In particular, it begins a crucial conversation: how can policy instruments, including but not limited to patents, address the particular barriers created by social network failures-(1) lack of social-cognitive ties; (2) cognitive distance; and (3) different (or clashing) evaluative frames-as identified in this Article?

\section{MARKET FAILURES IN INNOVATION}

Traditional justifications for granting intellectual property rights to innovators are grounded upon the failure of market mechanisms to efficiently supply knowledge goods. ${ }^{43}$ Both theoretical models of innovation and empirical studies find that market competition alone will generate investment in research and development that is quite below what is socially optimal. ${ }^{44}$ As Kenneth Arrow theorized in 1962, three interrelated characteristics of information and information-rich goods-(1) uncertainty; (2) inappropriability (or non-excludability); and (3) indivisibilities (or non-rivalry in consumption) - explain why markets will fail to produce socially optimal levels of innovation. ${ }^{45}$ First, a crucial feature of investment in $R \& D$ is great uncertainty about the likelihood of success of any given research project. Absent some form of insurance against failure, ${ }^{46}$ the market will tend to discriminate against high-risk, high-variance projects. ${ }^{47}$

The last two characteristics of information, inappropriability (or nonexcludability) and indivisibility (or non-rivalry in consumption), are commonly treated together as the "public goods" problem of information and

43. See, e.g., Brett M. Frischmann, Michael J. Madison, \& Katherine J. Strandburg, Governing Knowledge Commons, in Governing KNowledge Commons 12-13, 16 (Brett M. Frischmann et al. eds., 2014) (describing the traditional argument for intellectual property protection).

44. See, e.g., Arrow, supra note 1, at 619 (modeling underinvestment in knowledge goods); Bronwyn Hall, The Private and Social Returns to Research and Development, in Technology, R\&D, And the Economy 140-83 (Bruce L.R. Smith \& Claude E. Barfield eds., 1996); Nicholas Bloom, Mark Schankerman \& John Van Reenen, Identifying Technology Spillovers and Product Market Rivalry, 81 ECONOMETRICA 1347, 1349 (2013) (finding that "the (gross) social rate of return to R\&D exceeds the private return," which implies "under-investment in R\&D, with the socially optimal level being over twice as high as the level of observed R\&D"); Stephen Martin \& John T. Scott, The Nature of Innovation Market Failure and the Design of Public Support for Private Innovation, 29 REs. POL'y 437, 438 (2000); Richard Nelson, The Simple Economics of Basic Scientific Research, 49 J. PoL. ECON. 297, 297 (1959) (modeling underinvestment in basic scientific research).

45. Arrow, supra note 1, at 609.

46. See Arrow, supra note 1 , at 616 .

47. Arrow, supra note 1, at 616 ("By the very definition of information, invention must be a risky process, in that the output (information obtained) can never be predicted perfectly from the inputs."). 
information goods..$^{48}$ This problem can be summarized as follows: if information is to be produced by the market, innovators must be able to obtain revenues from the sale of information or of information-containing goods (or to "appropriate" the social benefits of their innovation). ${ }^{49}$ In turn, this requires sellers of information to be able to exclude other, nonpaying users (or "free riders") from accessing that information. ${ }^{50}$ But it is comparatively much more difficult to exclude others from using knowledge resources once these resources are disclosed than to exclude others from using real or personal property. This is because consumption of information is non-rivalrous: enjoyment of a particular piece of knowledge by any one person does not preclude its enjoyment by others. ${ }^{51}$ In contrast there are a sharply limited number of people who can simultaneously enjoy a parcel of land or an item of personal property.

A market in information itself will also be inefficient because of what researchers have termed Arrow's "disclosure [or information] paradox." ${ }^{52}$ Arrow explains the paradox as follows: "[T]here is a fundamental paradox in the determination of demand for information; its value for the purchaser is not known until he has the information, but then he has in effect acquired it without cost." 53 The disclosure paradox affects the ability of innovators to contract with others to commercialize their innovations. On the one hand, investors and manufacturers need access to the inventor's new knowledge in order to decide whether they want to invest in developing and commercializing the innovation. Yet, the innovator has no guarantee that, after she has disclosed her new knowledge, the putative investor or manufacturer won't simply take it for free. The paradox is thought to lead to an inefficient organization of labor-encouraging innovators to commercialize their own inventions even if they are not in the best position to do so, and discouraging $\mathrm{R} \& \mathrm{D}$ collaboration across firms. ${ }^{54}$

This market failure narrative justifies some form of governmental intervention in the market for information and information-rich goods. Patent rights are one such form of intervention: by enabling innovators to exclude others from using the fruits of their research and development, patents make information (more) appropriable. ${ }^{55}$ Patents are intended to address three problems identified in market failure analyses: the under-

48. See, e.g., Brett M. Frischmann, An Economic Theory of Infrastructure and Commons Management, 89 MinN. L. REv. 917, 939-49 (2005).

49. See, e.g., id. at 943-46.

50. See, e.g., id. at 946.

51. See, e.g., id.

52. See, e.g., Michael J. Burstein, Exchanging Information Without Intellectual Property, 91 Tex. L. Rev. 227, 229 (2012) (describing Arrow's disclosure paradox).

53. Arrow, supra note 1, at 615.

54. See, e.g., Jonathan M. Barnett, Intellectual Property as a Law of Organization, $84 \mathrm{~S}$. CAL. L. REv. 785, 816 (2011) (arguing that weak or no patent regimes can foster excessive (and inefficient) levels of integration in firms).

55. See, e.g., Nancy Gallini \& Suzanne Scotchmer, Intellectual Property: When Is It the Best Incentive System?, in 2 InNOvAtion POLICY AND THE ECONOMY 51, 54 (Adam B. Jaffe et al. eds., 2002). 
investment in $\mathrm{R} \& \mathrm{D}$, the disincentive for information disclosure between innovators and commercializers arising from Arrow's disclosure paradox, and the inefficient prioritization of research that can be kept as a trade secret. ${ }^{56}$ They do so by allowing the creation of a market in information and information-rich goods that fosters R\&D investment and transactions in information, and that guides innovative efforts towards inventions society values the most through the use of the price system. ${ }^{57}$ Patents, however, are not without costs. By putting a positive price on information, patents create deadweight loss-consumers who would otherwise purchase information-rich goods priced at the marginal cost of production are excluded from the market. ${ }^{58}$ The role of patent law in addressing specific types of market failures is depicted below in Figure 1.

Market Failure

\begin{tabular}{|l|l|}
\hline - Free-riding & $\begin{array}{l}\text { - Monopoly pricing through exclusive } \\
\text { property rights (patent law) }\end{array}$ \\
\hline $\begin{array}{l}\text { - Over-investment in secrecy } \\
\text { - Inefficient horizontal integration in } \\
\text { firms }\end{array}$ & $\begin{array}{l}\text { - Protection for disclosed information } \\
\text { through exclusive property rights } \\
\text { (patent law) }\end{array}$ \\
$\begin{array}{l}\text { Infficient transactions in } \\
\text { information }\end{array}$ & $\begin{array}{l}\text { - Inder-commercialization of } \\
\text { innovations }\end{array}$ \\
\hline
\end{tabular}

Figure 1: Designing Innovation Policy to Cure Market Failures

Patents, of course, are not the only type of governmental intervention that can correct market failures. For example, direct governmental subsidies of research and development in the form of grants or prizes can serve the same purpose. ${ }^{61}$ The latter two mechanisms solve the public goods problem of information not by making it more appropriable in the mar-

56. See, e.g., id. at 54-55.

57. See Demsetz, supra note 5, at 14 ("The indivisibility problem may very well be handled best by a private property system that reduces the cost of contracting and raises the cost of free-loading while, at the same time, it provides incentives and guidance for investment in producing information."); Kapczynski \& Syed, supra note 7, at 1908.

58. See, e.g., Gallini \& Scotchmer, supra note 55, at 54; Amy Kapczynski, The Cost of Price: Why and How to Get Beyond Intellectual Property Internalism, 59 UCLA L. Rev. 970, 982 (2012).

59. William Nordhaus provided the classic economic analysis of patent term, arguing that the optimal patent term balances incentives to encourage innovation against inefficiencies associated with monopoly rights. William Nordhaus, InVENTION, Growth and Welfare 76 (1969); see also Michael Abramowicz, The Danger of Underdeveloped Patent Prospects, 92 Cornell L. Rev. 1065, 1066-67 (2007); F.M. Scherer, Nordhaus' Theory of Optimal Patent Life: A Geometric Reinterpretation, 62 Am. Econ. Rev. 422, 427 (1972).

60. See, e.g., Ted Sichelman, Commercializing Patents, 62 Stan. L. Rev. 341, 341 (2010).

61. See, e.g., Daniel J. Hemel \& Lisa Larrimore Ouellette, Beyond the Patents-Prizes Debate, 92 Tex. L. Rev. 303, 303 (2013); Benjamin N. Roin, Intellectual Property Versus Prizes: Reframing the Debate, 81 U. CHI. L. Rev. 999, 1001 (2014); Steven Shavell \& 
ket but by severing compensation for research and development from any charge to the users of information. ${ }^{62}$ This is how basic research is (mostly) funded. ${ }^{63}$ The products of basic research are not sold on the market but are generally available to the public. Much has been written about the comparative advantages and disadvantages of prizes vs. grants vs. patents in fostering innovation. ${ }^{64}$ What all of these writings have in common is that market failure analyses serve as the lodestar in all comparative evaluations of the merits and demerits of different institutional arrangements to foster innovation. ${ }^{65}$ The question all comparative analyses ask is: given our understanding of why markets fail to optimally induce innovation, which type of intervention can best cure market failures?66 For example, commentators who argue that prizes are superior to patents provided the government can accurately calculate the size of the reward, emphasize the ability of prizes to place new knowledge in the public domain thus avoiding the deadweight loss of monopoly pricing. ${ }^{67}$ The centrality of market failure analyses in developing and comparing different policy interventions to foster innovation make it all the more pressing to uncover two unstated assumptions in market failure models: the free flow of information assumption, and the exogenous treatment of ideas. I undertake this task in the next subsection.

\section{A. Assumption One: Information's Tendency to Flow Freely}

Arrow's foundational work, and the work of many law and economics scholars that build upon it, begins with the fundamental assumption that knowledge has a tendency to diffuse across society once it is revealed and that efforts to control its spread will, at best, minimize but not completely contain it. Before illustrating this point, let us be clear that Arrow himself emphasized that this characteristic of information was altogether desirable from a static efficiency perspective (that is, taking a snapshot of society). ${ }^{68}$ From a static perspective, existing information would be put to its most efficient use if it were freely available to anyone who wants to use it. ${ }^{69}$ But from a dynamic perspective (taking into account the effect of free access on future producers of knowledge goods), free distribution of

Tanguy Van Ypersele, Rewards Versus Intellectual Property Rights, XLIV J. L. EcON. 525, 525 (2001).

62. See, e.g., Hemel \& Oullette, supra note 61.

63. See generally Nelson, supra note 44.

64. See, e.g., Hemel \& Ouelette, supra note 61; Roin, supra note 61; Shavell \& Ypersele, supra note 61.

65. See, e.g., Hemel \& Ouelette, supra note 61, at 304-05; Roin, supra note 61, at 1001-03; Shavell \& Ypersele, supra note 61, at 526-27.

66. See Gallini \& Scotchmer, supra note 55, at 52.

67. See, e.g., Roin, supra note 61, at 1025; Shavell \& Ypersele, supra note 61, at 529-30.

68. See Arrow, supra note 1, at 616-17 ("[A]ny information obtained . . should, from the welfare point of view, be available free of charge (apart from the cost of transmitting information). This insures optimal utilization of the information but of course provides no incentive for investment in research.").

69. See Arrow, supra note 1, at 616-17. 
information now existing creates disincentives to the production of new information. ${ }^{70}$ The debate as to whether prizes or patents are optimal innovation incentives centers in large part on whether limiting the spread of information by propertizing it through patent law is more efficient in incentivizing the creation of new information than rewarding information-creators with prizes, while placing new information in the "public domain."71 For the purpose of this Article, however, the merits and demerits of arguments on each side of the debate are not important. What is important is that Arrow's initial treatment of information as freely diffusible has been taken up both by proponents of intellectual property rights and by proponents of alternative mechanisms to incentivize innovation, who prioritize access to new information. For this reason, I begin by illustrating Arrow's approach to the nature of information. I then provide examples of how this treatment of information as freely diffusible has been taken up both by proponents and detractors of strong intellectual property rights.

In his elaboration of why it is difficult to create an efficient market for information, Arrow explains:

The cost of transmitting a given body of information is frequently very low.... In the absence of special legal protection, the owner cannot, however, simply sell information on the open market. Any one purchaser can destroy the monopoly, since he can reproduce the information at little or no cost. . . . With suitable legal measures, information may become an appropriable commodity. Then the monopoly power can indeed be exerted. However, no amount of legal protection can make a thoroughly appropriable commodity of something so intangible as information. The very use of the information in any productive way is bound to reveal it, at least in part. ${ }^{72}$

Note how Arrow leads his analysis with two clearly stated propositions. First, transmitting information is cheap and easy. Second, even with "suitable legal measures" (i.e. intellectual property rights), information will continue to spread. In fact, it is in the nature of information as an intangible, hard to delineate commodity, to do so. Indeed, Arrow's analysis in the quoted paragraph is focused on the difficulties in containing knowledge spillovers (or positive externalities) from innovative activity-even though Arrow doesn't use the term "spillovers."73

70. See, e.g., Arrow, supra note 1, at 615; Demsetz, supra note 5, at 10-11; Brett M. Frischmann, The Pull of Patents, 77 Fordham L. Rev. 2143, 2156 (2009). In his critique of Kenneth Arrow's analysis in "Economic Welfare and the Allocation of Resources for Invention" for failing to engage in comparative institutional analysis, Harold Demsetz emphasizes precisely these dynamic effects of widespread use of now existing information on its future production. Demsetz, supra note 5, at 11 ("Since one of the main functions of paying a positive price is to encourage others to invest the resources needed to sustain a continuing flow of production, the efficiency with which the existing stock of goods or information is used cannot be judged without examining the effects on production.").

71. See, e.g., Shavell \& Ypersele, supra note 61 , at 525.

72. Arrow, supra note 1, at 614-15 (emphasis added).

73. Knowledge spillovers are simply benefits from R\&D (or positive externalities) that "spill over" for third parties to exploit without having to pay for their use. For example, 
This focus on knowledge spillovers, and more specifically on how to contain them, has been the motivation of much of law and economics literature in patent law. ${ }^{74}$ Many scholars who emphasize the crucial role of intellectual property rights in incentivizing innovation-by giving creators control over information goods they have created-build on Harold Demsetz's seminal article, Toward a Theory of Property Rights. ${ }^{75}$ There, Demsetz suggested that an efficient property system would allow owners to internalize externalities (both positive and negative) arising from their productive activities. ${ }^{76}$ This argument, as applied to information goods, has led to an emphasis on how to enable innovators to internalize spillovers that flow naturally from knowledge goods' or information's tendency to "be free." 77 This persistent focus on spillovers in the law and economics literature on IP conjures up a view of information goods as naturally and easily sharable. ${ }^{78}$ Indeed, although Demsetz criticizes Arrow for not engaging in comparative institutional analysis when condemning property rights as inefficient, he nonetheless agrees with Arrow's characterization of information as "freely available" in the absence of private property rights. ${ }^{79}$ Legal scholars writing within this traditional economic framework often make the same background assumptions about the natural shareability of new information. ${ }^{80}$

"the very use of the information in any productive way," as Arrow notes, at a minimum is thought to reveal to competitors that a particular innovation is possible-an intra-industry spillover. Arrow, supra note 1, at 615 . And, as Lemley and Frischmann explain, spillovers can also take place inter-industry since "[w]ork done in one field, such as defense or space science, may have benefits in seemingly unrelated fields such as materials science. The inventor may have no interest in or even awareness of the benefits her idea has in these unrelated fields.” Brett M. Frischmann \& Mark A. Lemley, Spillovers, 107 Colum. L. REv. 257, 261 (2007).

74. See, e.g., Frischmann \& Lemley, supra note 73, at 291-93 (describing the focus, in the academic literature on patent law, on how to contain knowledge spillovers).

75. See Harold Demsetz, Toward a Theory of Property Rights, 57 Am. Econ. Rev. 347 (1967).

76. Id. at 348

77. R. Polk Wagner, Information Wants To Be Free: Intellectual Property and the Mythologies of Control, 103 Colum. L. Rev. 995, 999 (2003) ("It turns out that information does 'want to be free.'") (emphasis added) (quoting Paulina Borsook, Opinion, Art's Cold Welcome on the Web, N.Y. Times, Feb. 23, 2001).

78. The argument here is not that spillovers are unimportant. Rather, the persistent focus on how information tends to spread unless controlled (i.e., on spillovers) has diverted attention from all the ways in which information remains confined to the communities that produce it and those others in their close network. It has also diverted attention from studying how this confinement often has negative consequences for advances in our understanding of complex problems. It is only by foregrounding the "sticky" nature of knowledge, and its uneven distribution in communities of practice that often do not interact with each other that we can begin to understand how to design innovation tools that will allow knowledge to flow more freely and productively across communities.

79. Demsetz, supra note 5, at 11, 12. Demsetz, however, suggested that patents have an advantage over government subsidies in guiding the allocation of private resources to the most valuable innovations because patents are responsive to market signals (through prices) from consumers to producers. Demsetz, supra note 5, at 12-13.

80. For example, R. Polk Wagner argues that the "fencing' of information is a remarkably futile proposition," because of a type of information spillover, which he terms "Type III" information, that cannot be captured by intellectual property rights. Wagner, supra note 77, at 999, 1004-05. And Oren Bar-Gill and Gideon Parchomovsky build on 
Scholars who study open innovation, and who often oppose efforts to propertize information goods, nevertheless take a similar view of the natural shareability of information. ${ }^{81} \mathrm{~A}$ central concept in the literature on open innovation is the idea of the "public domain." 82 As Pamela Samuelson and James Boyle have remarked, multiple conceptions of the public domain coexist in the legal literature. ${ }^{83} \mathrm{But}$ most of them are rooted in analogies to open roads and parks, or in metaphors such as "free as the air to common use" that suggest a homogeneous space where information resides, free for the taking. ${ }^{84}$ Even those conceptions of the public domain that recognize its topography and focus on its capacity to enable innovators to recombine and re-assemble knowledge resources tend to assume that lack of private control and low access costs (enabled by technological advances) are sufficient to give rise to such participation. ${ }^{85}$

For example, in his pivotal work The Future of Ideas, Lawrence Lessig argued that a key question for the management of knowledge resources is "not whether the market or the state should control a resource, but whether that resource should remain free." 86 In turn, a resource is free if no permission is needed for its use, or if such permission is granted neu-

Arrow's information paradox to propose the creation of property rights in ideas (in addition to the now-existing intellectual property protection for inventions, understood as the concrete application of ideas). Oren Bar-Gill \& Gideon Parchomovsky, A Marketplace for Ideas?, 84 Tex. L. Rev. 395, 396-97 (2005).

81. An important exception is recent work by Frischmann, Madison, and Strandburg to map and characterize "knowledge commons"-a project that calls for detailed case studies of how communities of innovators create and share knowledge on the ground, including by mapping their interactions with institutional structures and incentives. Frischmann et al., supra note 43 , at ix-x.

82. See, e.g., James Boyle, The Second Enclosure Movement and the Construction of the Public Domain, 66 Law \& Contemp. Probs. 33 (2003); David Lange, Recognizing the Public Domain, 44 Law \& Contemp. Probs. 147 (1981); Jessica Litman, The Public Domain, 39 Emory L. J. 965 (1990); Pamela Samuelson, Enriching Discourses on Public Domains, 55 Duke L. J. 783 (2006).

83. Boyle, supra note 82, at 38-39; Samuelson, supra note 82, at 785-86.

84. Int'l News Serv. v. Associated Press, 248 U.S. 215, 250 (1918) (Brandeis, J., dissenting) ("The general rule of law is, that the noblest of human productions-knowledge, truths ascertained, conceptions, and ideas-become, after voluntary communication to others, free as the air to common use."); see also Michael D. Birnhack, More or Better? Shaping the Public Domain, in The Future of the Public Domain 60 (Lucie Guibault \& P. Bernt Hugenholtz eds., 2006) ("The public domain is . . where knowledge is created and where it lies awaiting new interpretations, new applications and new meanings. It is not a graveyard, but a playground for speech-experiments.").

85. See, e.g., Joel Mokyr, The Contribution of Economic History to the Study of Innovation and Technical Change: 1750-1914, in 1 HandBook of THE ECONOMICs OF TeCHNICAL Change 15 (Bronwyn Hall \& Nathan Rosenberg eds., 2010) ("Because total social knowledge equals the union of all individual pieces of knowledge, the knowledge available for technological advances was increasing, provided that those who could make best use of it were able to access it. ... What has assured the decline in access costs is that the technology of access itself has been improving."); Boyle, supra note 82, at 48 ("But we could hope that much of [intellectual and inventive production] would be both free of centralized control and low cost or no cost. When the marginal cost of production is zero, the marginal cost of transmission and storage approaches zero, the process of creation is additive, and much of the labor doesn't charge-well, the world looks a little different.").

86. Lawrence Lessig, The Future of Ideas: The Fate of the Commons in a Connected World 12 (2001). 
trally. ${ }^{87}$ Lessig focuses on how the emergence of the internet facilitates decentralized innovation by creating a commons where variously motivated individuals have the opportunity to "draw upon resources without connections, permission, or access granted by others." 88 The key step in Lessig's account is access-conceptualized as the opposite of control. Once information is released from the chains of private control, individuals will "create-remixed films, new forms of music, digital art, a new kind of storytelling, writing, a new technology for poetry, criticism, political activism - and then, through the infrastructure of the Internet, share that creativity with others." 89 In The Wealth of Networks, a path-breaking work that brought the idea of "social production" of knowledge to the forefront of intellectual property studies, Yochai Benkler describes the rise of non-market models of innovation-made possible by the drastic fall in access and dissemination costs spurred by the development of the internet (what I have termed technological access costs). ${ }^{90}$ Like Lessig, Benkler focuses our attention on the choice between access and control: "To what extent will resources necessary for information production and exchange be governed as a commons, free for all to use and biased in their availability in favor of none?"91 The low costs of technological access have changed the innovation landscape, so that "[a]ny person who has information can connect with any other person who wants it, and anyone who wants to make it mean something in some context, can do so." 92 Economic historian Joel Mokyr takes a similar approach, arguing that increasing specialization coupled with drastically reduced access costsbrought about by the printing press, the internet, and the expansion of open science-have increased "total social knowledge" by ensuring that "those who could make best use of it were able to access it." 93

These accounts take the main constraints to the productive recombination and use of information to be private control and lack of technological access and, in some descriptions, also price ${ }^{94}$ Once information is free of these constraints, the main limits on the rate and direction of innova-

87. $I d$.

88. Id. at 85 .

89. Id. at 9.

90. Yochai Benkler, The Wealth of Networks: How Social Production Transforms Markets AND Freedom 1-4 (2006).

91. Id. at 23.

92. Id. at 32 .

93. Mokyr, supra note 85 , at 15 .

94. See, e.g., BENKLER, supra note 90 , at 139 ("[I]mprovements in the degree to which these liberal commitments are honored and practiced emerge from new behaviors made possible and effective by the networked information economy. These behaviors emerge now precisely because individuals have a greater degree of freedom to act effectively, unconstrained by a need to ask permission from anyone.") (emphasis added); Amy Kapczynski, Access to Knowledge: A Conceptual Genealogy, in ACCess to KNOWLedge IN THE Age of Intellectual Property 17, 31 (Gaëlle Krikorian \& Amy Kapczynski eds., 2010) (describing the Access to Knowledge movement's conceptualization of the public domain as synonymous with what is "open to all" both in terms of permission and price). 
tion are given by human creativity itself. ${ }^{95}$ But, as this Article shows, human capacity is intimately bound with the communities in which each individual is embedded and their knowledge structures and practices. ${ }^{96}$ To put it differently, we've stopped short of asking the next set of significant questions: What does it mean in fact for information to be free of legal encumberments? How is it in fact accessed by social actors? Are there any other barriers to "accessibility"? And, switching vantage points from seeking those conditions that enable individual autonomy and creativity to those that optimize resource management, why have complex problems resisted study and treatment? As Julie Cohen reminds us in the context of copyright policy, "[i]f creative practice entails the opportunistic exploitation of a set of environmental resources, copyright policy must pay close attention to the structure of that environment." 97 In the context of copyright theory, Cohen has called for a "sociology of creative practice" that is "relational and network-driven," and that recognizes that human creativity both shapes and is shaped by the cultural environment. ${ }^{98}$

\section{The New Institutional Economics and Transaction Costs Economics Approaches}

Admittedly, this description of how law and economics scholarship has tended to treat the flow of information is overly simplistic. Following market failure models of innovation, two very related schools of economic thought-Transaction-Costs Economics (TCE) ${ }^{99}$ and New Institu-

95. BENKLER, supra note 90 , at 52 ("Given the zero cost of existing information and the declining cost of communication and processing, human capacity becomes the primary scarce resource in the networked information economy."); LEssig, supra note 86. Both Benkler and Lessig's approaches are self-consciously individualistic. They are both concerned with individual freedom to participate in creative activities, defined as their capacity for autonomous action. BENKLER, supra note 90, at 52-53; Lessig, supra note 86, at $7-9,12$. In more recent work, Benkler has encouraged the further study of collaboration by paying close attention to advances in the fields of not only psychology but also organizational sociology. Yochai Benkler, Law, Policy, and Cooperation, in Government AND Markets: Toward a New Theory of Regulation 311 (Edward J. Balleisen \& David A. Moss eds., 2010) (calling for the design of interventions that "set[] the social context so that it facilitates cooperation among cooperators and allows selfish actors to be policed and incentivized in ways that do not undermine the intrinsic motivation of the more cooperative participants").

96. See infra Parts II, III. See also Roger Guimera, Brian Uzzi, Jarrett Spiro \& Luis A. Nunes Amaral, Team Assembly Mechanisms Determine Collaboration Network Structure and Team Performance, 308 SCIENCE 697, 697 (2005) ("Agents in creative enterprises are embedded in networks that inspire, support, and evaluate their work.").

97. Julie E. Cohen, Copyright, Commodification and Culture: Locating the Public Domain, in The Future of the Public Domain: Identifying the Commons in InformaTION LAW 154 (Lucie Guibault \& P. Bernt Hugenholtz eds., 2006).

98. Id. at $146-56$.

99. See, e.g., Oliver E. Williamson, Transaction-Cost Economics: The Governance of Contractual Relations, 22 J. LAw \& EcON. 233 (1979); Oliver E. Williamson, Transaction Cost Economics: The Natural Progression, 100 Am. Econ. Rev. 673 (2010); Steven Tadelis \& Oliver E. Williamson, Transaction Cost Economics, in HANDBOOK OF OrganizaTIONAL ECONOMICS 159 (2012). 
tional Economics (NIE) ${ }^{100}$ - have focused extensively on how transaction costs, and institutional environments and formal rules, respectively, influence market transactions, including information exchanges. Those who have studied access to information from this perspective have termed the costs of information flow "access costs." 101 Access costs as studied by NIE and TCE do not fully capture the barriers to information recombination that I describe in this Article. But leaving these concerns aside for now, TCE scholars often identify access costs to then minimize them, assuming that advances in information technology will soon make access costs negligible. ${ }^{102}$ As I show in Part III, simple access costs, that is, access to publicly-available information, are often kept high by a pervasive lack of social ties between communities with complementary information. ${ }^{103}$

From a transaction-costs approach then, one way to conceptualize this project is as identifying important, yet undervalued, transaction costs among communities of innovators. I have not explicitly named these barriers transaction costs in large part because traditional understandings of transaction costs are quite different from the social network barriers I describe in this Article. For example, TCE studies in law are most frequently deployed to explain a firm's "make or buy" decisions. ${ }^{104}$ TCE predicts that firms will make an innovation in house when transaction costs are high, but firms will buy the innovation in the market when transaction costs are low. ${ }^{105}$ In the first scenario, transaction costs are "internalized" and hierarchical decision-making replaces market transactions. ${ }^{106}$ But two of the social network failures that I describe in Part III (cognitive distance and different (or clashing) evaluative frames) can persist inside firm hierarchies and are reflected in firms' difficulties in managing teams with diverse professional or disciplinary backgrounds. ${ }^{107}$

Further, the social network failures described in this Article go beyond scholars' traditional conceptualization of access costs. Social network fail-

100. See, e.g., Oliver E. Williamson, Markets and Hierarchies: Analysis and Antitrust ImPLicAtions (1975); Oliver E. Williamson, The New Institutional Economics: Taking Stock, Looking Ahead, 38 J. Econ. Lit. 595, 597 (2000). Williamson describes New Institutional Economics as encompassing Transaction Costs Economics. Specifically, NIE is concerned with studying (1) the institutional environment (e.g. formal rules, and property rules in particular) and (2) governance structures that influence transactions among parties. TCE is concerned primarily with (2) above: analyzing governance structures and their impact on transaction costs.

101. See, e.g., Mokyr, supra note 85, at 15.

102. Id.; Fiona Murray \& Siobhán O'Mahony, Exploring the Foundations of Cumulative Innovation: Implications for Organization Science, 18 ORG. SCI. 1006, 1008 (2007) ("But for innovation to occur, knowledge must not just flow: Innovators must have the ability to actually combine or accumulate knowledge.").

103. See infra Part III.

104. See, e.g., Tadelis \& Williamson, supra note 99, at 161 ("TCE was transformed into an operational methodology by taking the "make-or-buy" decision to be the focal transaction.").

105. Id.

106. Id.

107. See infra Part III. 
ures have less to do with access to information than with barriers to the productive recombination of existing information to create new knowledge. We may term these barriers "access and recombination" costs. Fiona Murray and Siobhán O'Mahony recognize a similar gap in current organizational and economic analyses of cumulative innovation, calling innovation scholars to "shift their emphasis from studies of knowledge flows to examining the opportunities and constraints innovators confront as they attempt to reuse, recombine, and accumulate knowledge."108 What the case studies in Part III provide, then, is an in-depth exploration of the origin of these barriers, so that targeted policy levers can be designed to address them.

Despite these differences, the broader NIE approach has a lot in common with the network approach that I take here. In other work, I have taken an NIE approach to studying the emergence of interdisciplinary collaboration. ${ }^{109}$ Nevertheless, the network approach has some advantages over NIE approaches. In particular, network analysis generates new insights by shifting the unit of analysis from institutional environments and formal rules, to informal, fluid communities and informal social norms, which are often internalized by community members. ${ }^{110}$

It also bears emphasizing that other legal scholars have also challenged the free flow of information assumption in traditional economic models of innovation. For example, in his examination of the transfer of technology from university laboratories to the private sector, Peter Lee has emphasized how ongoing relationships between universities and companies were crucial to the transfer of tacit knowledge necessary to practice a patented innovation. ${ }^{111}$ Lee's research focuses on one important barrier to the free flow of information: codified knowledge, in the form of a pat-

108. Murray \& O'Mahoney, supra note 102, at 1006-07.

109. Laura Pedraza-Fariña, Constructing Interdisciplinary Collaboration: The Oncofertility Consortium as an Emerging Knowledge Commons, in Governing Medical KNowLEdge Commons (Katherine J. Strandburg, Brett M. Frischmann \& Michael J. Madison eds., 2017). The methodology in this work follows a modified template from Elinor Ostrom's work on natural resource commons. Michael J. Madison, Brett M. Frischmann \& Katherine J. Strandburg, Constructing Commons in the Cultural Environment, 95 CoRNELL L. REV. 657 (2010). Ostrom's approach is widely considered part of the NIE corpus.

110. Whether a "network approach" or a "new institutional economics" approach is better suited to understand social relations has been the subject of vigorous debates on the part of sociologists and economists. See, e.g., Rudolf Richter, New Economic Sociology and New Institutional Economics, in Essays on New Institutional Economics 51 (2015) (summarizing the debate). While economists emphasize transactions as the primary unit of analysis, sociologists emphasize the importance of understanding embedded, underlying social relations. See, e.g., Mark Granovetter, Economic Action and Social Structure: The Problem of Embeddedness, 91 Aм. J. Sociol., 481 (1985); Powell, (critiquing the transaction cost approach); Paul DiMaggio, Cultural Aspects of Economic Organization and Behavior, in Beyond the Market Place: Rethinking Economy and Society (R. Friedland \& A.F. Robertson, eds.1990) (emphasizing the importance of institutional culture); Williamson, supra note 100 [New Institutional Economics: Taking Stock] at 596-97 (describing four levels of social analysis and explaining that "level 1" analysis-the social embeddedness level-is taken as a given by most institutional economists).

111. Peter Lee, Transcending the Tacit Dimension: Patents, Relationships, and Organizational Integration in Technology Transfer, 100 CAL. L. REv. 1503, 1510-11 (2012). 
ent disclosure or a scientific publication, is often insufficient to teach others how to practice the invention. ${ }^{112}$ Similarly, Michael Burstein has challenged the corollary derived from Arrow's information paradox: that property rights in information are needed to foster transactions between innovators and commercializers. ${ }^{113}$ Burstein points to the multidimensional nature of information to argue that companies or inventors who want to sell their innovation can often disclose sufficient information about their innovation to potential developers to close a deal without revealing crucial details about how to practice the invention-thus enabling informational exchange without intellectual property protection. ${ }^{114}$ Both Lee and Burstein focus on the multidimensional nature of information. Lee emphasizes the tacit dimension of information, which makes information harder to communicate than predicted under the "traditional view" described in this Section. ${ }^{115}$ Burstein emphasizes how the multivalent nature of information allows information producers to simultaneously reveal and conceal crucial information about an invention. ${ }^{116}$ This Article builds upon these contributions but emphasizes a set of separate-yet understudied-barriers to the free flow of information. These barriers arise not from strategic moves by innovators to keep important aspects of an invention secret during negotiations but from the architecture of knowledge distribution itself: the division of knowledge in noninteracting communities with different priorities, ways of framing problems, and social norms.

As I show in Part IV, patent law doctrine itself, which is increasingly shaped by market failure models of innovation, also reflects the free flow assumption.

\section{B. Assumption Two: The Origin of Ideas}

Market failure models of innovation take "ideas" as the logical starting point. In other words, these analyses ask: assume you have an idea, how would you go about turning it into a marketable product? ${ }^{117}$ Corporations, teams, or individuals simply "have" ideas. Understanding how and why certain research and development investments lead to more innova-

112. Id. at 1509.

113. Burstein, supra note 52, at 247-48.

114. Burstein, supra note 52, at 247-48.

115. Lee, supra note 111, at 1523-24.

116. Burstein, supra note 52, at 247-48.

117. See generally Stephen J. Kline \& Nathan Rosenberg, An Overview of Innovation, in The Positive Sum Strategy: Harnessing Technology for Economic Growth 275, 285 (Ralph Landau \& Nathan Rosenberg eds. 1986) (describing the traditional "linear model" of innovation, which begins with the black box of "research" but does not explore the variables that influence how and what type of research a firm decides to undertake: "In this model, one does research, research then leads to development, development to production, and production to marketing."); see also Arrow, supra note 1, at 616 (the starting point of the analysis is the existence of a "desired new product or process" a firm wants to develop); John Freeman \& Jerome S. Engel, Models of Innovation: Startups and Mature Corporations, 50 CAL. MANAG. Rev. 94, 94 ("Innovation refers to a process that begins with a novel idea and concludes with market introduction."). 
tive outcomes while others fail or, in more colloquial terms, where particularly innovative ideas come from, is beyond the purview of market failure analyses of innovation. ${ }^{118}$

Although legal scholarship is paying increasing attention to the pathways connecting ideas to marketable products, following traditional market failure analyses, it has similarly neglected to examine the conditions that lead to the generation of innovative ideas in the first place. For example, Jonathan Barnett's treatment of intellectual property as a law of organization charts different facets of the innovation process. ${ }^{119}$ While the steps leading from an "idea" to its "market release" are carefully parsed and include "market analysis," "research and development," "prototyping and testing," "marketing," "production," and "distribution," the steps that precede the formulation of the creative idea are ignored. ${ }^{120}$

While market failure analyses of innovation, and law and economic analyses of innovation more broadly, tend to blackbox the origin of "good" ideas, legal opinions in patent law have tended to focus on a notion of the "inventor" that is divorced from current sociological and psychological understandings of creativity. Beginning with the now discarded notion that a "flash of genius" is necessary for creative output, and continuing with patent law's current skepticism towards "combination patents" (patents that combine elements from multiple patented inventions), ${ }^{121}$ legal analysis systematically contravenes two key findings from sociological literature about the origin of good ideas. First, innovation emerges from recombination: good ideas are quite often the result of unusual recombinations, rearrangements, and restructurings of elements from distant cognitive domains. ${ }^{122}$ In this context, it makes little sense to single out innovations that combine known elements from existing patents for special negative treatment. Second, two of the most important hurdles to breakthrough innovation to address complex problems are finding a problem to be solved and framing this problem in a way that can be solved with existing techniques (or that points the way for new tech-

118. An important and growing body of literature has begun to harness the psychology of creativity to counteract the assumption that ideas are exogenous to analyses of innovation. See, e.g., Stephanie Plamondon Bair, The Psychology of Patent Protection, 48 Conn. L. Rev. 297 (2015); Jeanne C. Fromer, A Psychology of Intellectual Property, 104 Nw. U. L. Rev. 1441 (2010); Gregory N. Mandel, To Promote the Creative Process: Intellectual Property Law and the Psychology of Creativity, 86 Notre Dame L. Rev. 1999 (2011); Andres Sawicki, Risky IP, 48 Loy. U. Chi. L. Rev. 81 (2016); see also Jessica Silbey, The Eureka Myth: Creators, Innovators, and Everyday Intellectual Property 5-6 (2015).

119. Barnett, supra note 54, at 811. See also Michael Mattioli, The Data Pooling Problem, 32 BeRKeley TECH. L.J. (forthcoming, 2017) (analyzing the challenges, in Big Data innovation, of pooling unpublished information privately held by multiple parties).

120. Barnett, supra note 54, at 790-91; see also Kieff, supra note 3, at 735-37 (emphasizing the "commercialization theory" of patents whereby patents are enforced by a property rule to help facilitate commercialization of the invention, after it has been made).

121. See infra Part IV.

122. See infra Parts II, III. 
niques to be developed). ${ }^{123}$ For example, before the Kadison-Singer problem described in the introduction was a "problem to be solved," Kadison and Singer had to do the crucial work of formulating it as such. And before the problem could be fully solved, it had to be reframed (or translated) from a physics/quantum mechanics problem to one of computer science. ${ }^{124}$ But the patent law doctrines of obviousness and utility focus almost exclusively on problem-solving. ${ }^{125}$ As a consequence, two steps that are often critical to the formulation of good ideas are underappreciated and likely under-rewarded by current patent law doctrine.

I return to doctrinal implications in Part IV, which provides in-depth analysis of how incorrect assumptions about the free flow of information and the origin of ideas permeate patent law doctrine and proposes specific doctrinal solutions. But in order to fully appreciate the real-world importance of correcting mistaken assumptions about information flow and the origin of ideas, the next two Parts of this Article survey current sociological research on social networks and innovation (Part II) and work out a taxonomy of different types of social barriers to information flow and idea generation in three separate case studies (Part III). Taken together, these barriers to information and idea generation represent important, yet unexamined, social network failures in innovation.

\section{SOCIAL NETWORKS AND INNOVATION: FROM BROKERAGE TO STRUCTURAL FOLDS}

The role of social relationships in the creation, transmission, and adoption of new information has long been a subject of study in sociology. ${ }^{126}$ A growing body of theoretical and empirical research shows that the networks created by social relationships "influence the efficacy and efficiency by which individuals and collectives create knowledge by affecting their ability to access, transfer, absorb, and apply knowledge."127 These studies have collectively been termed "knowledge networks" research. ${ }^{128}$ A knowledge network is a set of nodes interconnected by relationships. Nodes are locations in the social network where particular types of knowledge are stored. Although nodes can be knowledge elements (such as patents or products) or "non-human repositories of knowledge" (such as databases), for the purpose of this Article, I will focus on the nodes that are most studied by social scientists: those composed of individuals or social collectives, such as teams and organizations. Relationships

123. See infra Parts II, III.

124. See infra Part III.B.

125. See infra Part IV.

126. See, e.g., Gautam Ahuja, Collaboration Networks, Structural Holes, and Innovation: A Longitudinal Study, 45 Admin. ScI. QuART. 425, 426 (2000) ("Recently, however, a few pioneering studies have explored network structure from the perspective of innovation generation.") (internal citations omitted); Ronald S. Burt, Structural Holes and Good Ideas, Aм. J. Soc. 349, 351-52 (2004) [hereinafter Structural Holes].

127. Corey Phelps, Ralph Heidl \& Anu Wadhwa, Knowledge, Networks, and Knowledge Networks: A Review and Research Agenda, 38 J. Mgmt. 1115, 1117 (2012).

128. See id. 
among nodes both facilitate and restrict the creation, transfer, and absorption of knowledge. ${ }^{129}$

\section{A. How Information Flows: Structural Holes and BROKERAGE IN INNOVATION}

Crucial insights into how social relations impact the distribution of information (and hence the direction and pace of innovation) come from work by sociologist Ronald Burt. Burt identified one particular feature in the architecture of social networks-structural holes - as a key explanatory variable for the outcome of market competition-including identifying winners and losers in product innovation and marketing. ${ }^{130}$ Structural holes are discontinuities in social relationships. Structural holes can be conceptualized as a void in the information matrix that prevents the free flow of information among groups. For example, a structural hole is present when two or more communities with potentially complementary information nonetheless contain no or very few members who interact with each other across community lines. Structural holes that divide clusters of dense social connections are not a rare occurrence but rather a defining feature of our social structure. ${ }^{131}$ Burt hypothesized that "people who stand near the holes in a social structure are at higher risk of having good ideas[,]" 132 by virtue of having access to more diverse information and "alternative ways of thinking and behaving." 133 These actors, referred to as "brokers"134 or "boundary spanners" 135 in the terminology of sociology of networks, can leverage their access to multiple knowledge communities to come up with ideas that others see as unusually "creative."136

129. See, e.g., Peter R. Monge \& Noshir S. Contractor, Theories of CommuniCATION NETWORKS 35 (2003).

130. Ronald S. Burt, Brokerage and Closure: An Introduction to Social Capital (2005) [hereinafter Brokerage and Closure]; Structural Holes, supra note 126 , at 388 .

131. Structural Holes, supra note 126, at 351. ("The defining features of the social structure are clusters of dense connection linked by occasional bridge relations between clusters."); see infra Figure 2.

132. Structural Holes, supra note 126, at 349.

133. Structural Holes, supra note 126, at 349-50.

134. See, e.g., Brokerage And Closure, supra note 130; Lee Fleming \& David M. Waguespack, Brokerage, Boundary Spanning, and Leadership in Open Innovation Communities, 18 Org. SCI. 165, 165 (2007).

135. See, e.g., Rob Cross, Chris Ernst \& Bill Pasmore, A Bridge Too Far? How Boundary Spanning Networks Drive Organizational Change and Effectiveness, 42 Org. DynamICS 81, 88 (2013); Fleming \& Waguespack, supra note 134.

136. See, e.g., Structural Holes, supra note 126, at 388-89. 


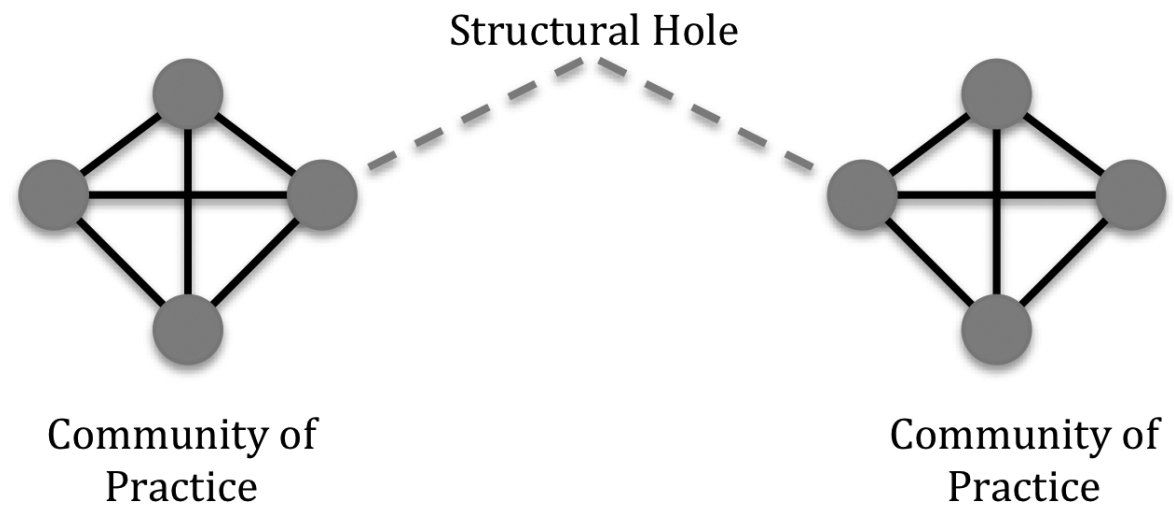

Figure 2: Structural Holes in Information Space

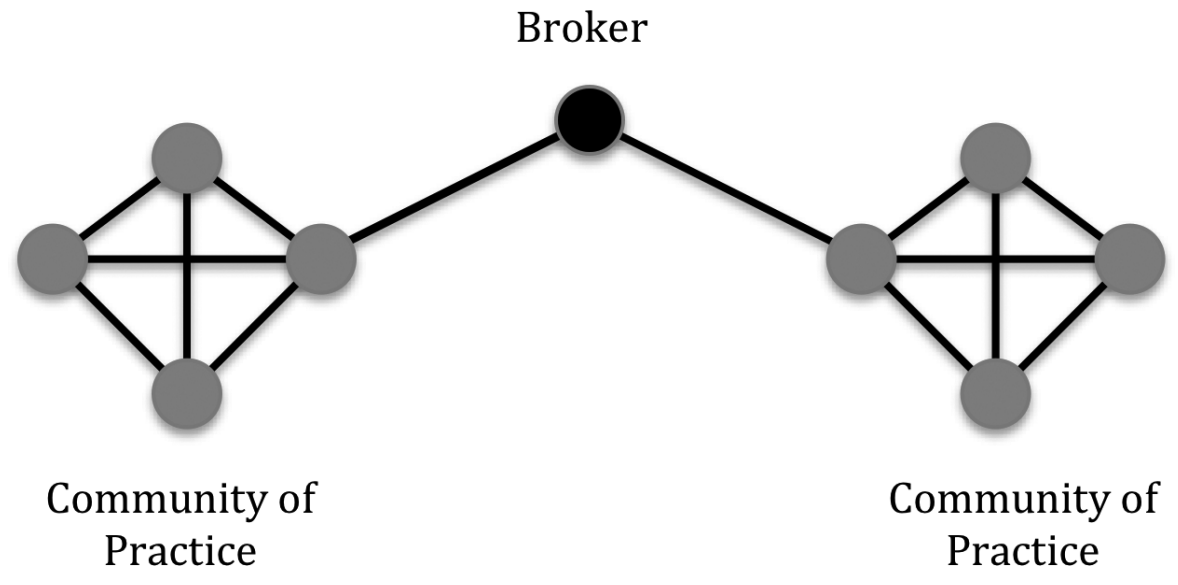

Figure 3: Brokers Occupy Structural Holes in Information Space

The concepts of "structural holes" and "brokerage" provide two theoretical contributions that challenge the "free flow" assumptions behind traditional market failure models of innovation and that shed new light on the origin of breakthrough ideas. First, because the architecture of knowledge distribution is not smooth but lumpy, information that is nominally accessible to the public - in the sense that it is not purposefully kept secret-is often not meaningfully accessible to innovators. Structural holes in our social relationships retard the meaningful flow of useful information across communities with few or no shared ties. As Burt puts it: "Information does not spread evenly across the competitive arena. It isn't that players are secretive, although that too can be an issue. The issue is that players are unevenly connected with one another [and] are attentive to the information pertinent to themselves and their friends . ..."137 Understanding how those structural holes are created, maintained, and bridged is an important goal of many studies in the sociology of networks.

137. Ronald S. Burt, Structural Holes: The Social Structure of CompetiTION 13 (1992). 
Second, the emergence of "new ideas" is strongly influenced by the lumpy architecture of knowledge distribution. In this view, innovation emerges out of a process of "recombinant search," where an individual's position in the network determines how she will search for information and what type of information she will have most ready access to and find most valuable. ${ }^{138}$ Innovators in a privileged ("brokerage" or "bridging") position in the network come up with the "best" ideas because they have access to (and thus are able to combine) diverse elements from unconnected communities. ${ }^{139}$

The Kadison-Singer problem described in the introduction is an additional example of brokerage. Indeed, it was only through the shared connections of mathematician Gil Kalai to both computer science and mathematics communities that the Kadison-Singer problem "migrated" from mathematics to computer science. ${ }^{140}$ In this context, Kalai "brokered" connections between mathematics and computer science by transporting a problem from one community to another and by translating the Kadison-Singer problem's mathematical formulation into a formulation that could be understood — and eventually solved — by computer scientists.

Thus far, I have focused (as does Burt) on an individual or entrepreneur's position in the network as determining her ability to come up with good ideas-or to act as a "broker." In other words, I have focused on the effect of an individual's social network on her own creativity. But there is a limit to the ability of a single person to successfully recombine elements from distant communities, even if she has social connections to members in these communities. There are two reasons for this: first, any individual will be cognitively limited in her ability to understand disparate fields of study. ${ }^{141}$ Second, acquiring expert skills in any given field requires "learning by doing"- that is, embeddedness in the relevant community of experts. ${ }^{142}$ It will be rare for a single individual to have access

138. See, e.g., Lee Fleming, Recombinant Uncertainty in Technological Search, 47 MgMt. SCI. 117, 118 (2001).

139. Empirical studies by Burt and others have found support for the structural holes hypothesis in multiple contexts. See, e.g., Structural Holes, supra note 126, at 377 (showing that managers who broker connections across structural holes in their organization are more likely to have ideas that top managers consider "good ideas"); Lee Fleming, Santiago Mingo \& David Chen, Collaborative Brokerage, Generative Creativity, and Creative Success, 52 Admin. ScI. Q. 443, 447 (2007) (showing, using data from utility patents, that an inventor "is more likely to create new combinations if he or she brokers relations between otherwise disconnected collaborators"); Jill E. Perry-Smith, Social Yet Creative: The Role Of Social Relationships in Facilitating Individual Creativity, 49 Acad. OF MgmT. J. 85, 96-98 (2006) (finding that individuals in a brokerage position are more creative than those whose contacts remained inside a particular node, as rated by knowledgeable observers).

140. See, e.g., Klarreich, supra note 15, at 1; Mackenzie, supra note 19.

141. Phelps, Heidl \& Wadhwa, supra note 127, at 1144 ("[T]o the extent increasing centrality provides access to more diverse information, actors may need to expend greater cognitive effort and resources to understand and utilize this information.").

142. See, e.g., Laura G. Pedraza-Fariña, Understanding the Federal Circuit: An Expert Community Approach, 30 Berkeley TeCH. L. J. 89, 115 (2015) (collecting sources on the sociology of expertise and the importance of "learning by doing"). 
to both codified and tacit knowledge from more than two or three disparate communities of practice. ${ }^{143}$ These limitations are of course magnified in the context of complex problems that require understanding and embeddedness in not just two but three or more disciplines. Understanding these two limitations has shifted the unit of analysis in social network studies from the work of individuals to that of teams-which is the focus of the next subsection. ${ }^{144}$

\section{B. Where Do Good Ideas Come From? Structural Folds and Team Creativity}

Until recently, social network research on team creativity and success was split along two research traditions. One tradition emphasized the importance of strong ties among team members (such as the strong ties that connect members of each community of practice depicted in Figures 1 and 2). Strong ties among team members were hypothesized to lead to team cohesion and to foster the development of a common research culture and a set of social norms, which in turn led to higher level of trust among team members. Theories of how cohesive groups facilitate innovation emphasize the crucial role of trust in fostering the disclosure and acceptance of new ideas without fears of free riding or shirking. ${ }^{145}$ Dense ties among group members are also thought to lower coordination costs. ${ }^{146}$ On the other hand, another research tradition emphasizes the importance of diversity over strong ties. ${ }^{147}$ Team diversity is predicted to increase team performance by bridging structural holes thus fostering the migration and recombination of ideas, methodologies, and resources from different communities of practice.

Trust and diversity, however, often work in opposite directions-trust increases as background diversity decreases. ${ }^{148}$ Teams whose members belong to the same research tradition-that use the same research tools and prioritize similar research questions-will enjoy higher levels of trust than teams whose members have diverse expert backgrounds. But exces-

143. See, e.g., id. at 114 (describing studies on the role of tacit knowledge in expert communities); see also Lee, supra note 111, at 1523-29 (collecting sources on studies on tacit knowledge).

144. See, e.g., Mary L. Disis \& John T. Slattery, The Road We Must Take: Multidisciplinary Team Science, 2 ScI. Trans. MED. 1 (2010); Stephen M. Fiore, Interdisciplinarity as Teamwork - How the Science of Teams Can Inform Team Science, 39 Small Group Res. 251, 251-77 (2008); Stefan Wuchty, Benjamin F. Jones \& Brian Uzzi, The Increasing Dominance of Teams in Production of Knowledge, 316 SCIENCE 1036, 1036-38 (2007).

145. See, e.g., Lee Fleming, Charles King III \& Adam I. Juda, Small Worlds and Regional Innovation, 18 ORG. SCI. 938, 940-41 (2007); Brian Uzzi \& Jarrett Spiro, Collaboration and Creativity: The Small Worlds Problem, 111 Aм. J. Soc. 447, 462-63 (2005).

146. See, e.g., Brian Uzzi, Social Structure and Competition in Inter-Firm Networks: The Paradox of Embeddedness, 42 Admin. ScI. Q. 35, 48-49 (1997).

147. See, e.g., Vedres \& Stark, supra note 29, at 1154 ("[B]usiness groups might elect to forgo high density within the group in favor of maintaining more weak ties to firms outside the group. Such a strategy of sacrificing density for diversity economizes network resources by reducing the number of redundant ties.").

148. See, e.g., Francesco Ramella, Sociology of Economic Innovation 135-37 (2016) (summarizing research on trust and diversity in teams). 
sive cohesion in such teams hinders "the circulation of non-redundant knowledge and the production of original ideas, and instead favors group conformity." 149 The bridging ties of diverse teams avoid this problem by ensuring that non-redundant, complementary knowledge is available to the team. At the same time, diverse teams are less likely than homogeneous ones to enjoy high levels of trust because membership in different research traditions-with their accompanying different research tools and priorities-is predicted to create communication and coordination difficulties. As Balazs Vedres and David Stark put it: "Brokerage/connectivity provides access to ideas and information but in itself lacks the means for implementation. Closure/cohesion provides the means of coordination but lacks diversity for discovery." 150 Cohesive groups thus have an "idea problem," 151 while brokered communities have an "action [or coordination] problem." 152

A recent, third line of research aims to reconcile these two research traditions by emphasizing that "innovation involves a combination of close familiarity and diversity." 153 In an influential series of papers, Mathijs de Vaan, David Stark, and Balazs Vedres criticize and build upon the concept of structural holes and brokerage. ${ }^{154}$ The authors emphasize that idea or information migration across communities of practice (through brokerage) is often insufficient to generate breakthrough innovations. ${ }^{155}$ De Vaan, Stark and Vedres's critique of Burt's concept of brokerage in many ways mirrors my own critique of market failure models of innovation for assuming that ideas are simply "out there," exogenous to relevant economic analyses of innovation. ${ }^{156}$ The authors criticize Burt for reducing idea generation to idea migration from one community to another, but failing to engage with how new, unusual recombinations (or ideas) arise in the first place. ${ }^{157}$ As the authors argue: "Instead of importing ideas or information, the challenge is to generate knowledge." 158 To do so, it is not enough for different communities to be in "long-distance

149. Id. at 137.

150. Vedres \& Stark, supra note 29, at 1154.

151. Vedres \& Stark, supra note 29, at 1154.

152. Vedres \& Stark, supra note 29, at 1154.

153. Vedres \& Stark, supra note 29, at 1155.

154. Mathijs de Vaan, Balazs Vedres \& David Stark, Game Changer: The Topology of Creativity, 120 Ам. J. Soc. 1144 (2015); Vedres \& Stark, supra note 29.

155. Vedres \& Stark, supra note 29, at 1151 ("Whereas this brokerage-plus-closure perspective sees innovation as importing and implementing ideas, we offer an alternative conception of entrepreneurship as recombination.").

156. Vedres \& Stark, supra note 29, at 1151 ("In our view, truly innovative ideas-in the first instance, a fresh conceptualization of the problem itself-are not free-floating outside the group.").

157. De Vaan, Vedres \& Stark, supra note 154, at 1151-52 ("Whereas the transmission model of networks refers to how ideas flow, structural folding refers to how ideas are generated. In the former view, networks function as a kind of transportation system, moving information from one social location to another, transplanting the kernel of an idea to organizationally more nourishing conditions. Structural folding, by contrast, is more of a production process where new problems are conceptualized as new resources are identified.") (emphasis added) (internal citations omitted).

158. Vedres \& Stark, supra note 29, at 1151. 
contact [with] casual access" to information to encourage the smooth flow of information among them (as is the case in brokerage). ${ }^{159}$ Rather, "generating new problems, new knowledge, and new capabilities (as opposed to transferring already accepted ideas)" 160 requires deep and frequent interaction between groups with different cognitive repertoires. Such collaboration, however, is only possible through the interaction of groups with both overlapping memberships and diverse cognitive styles and backgrounds. This is the key contribution in de Vaan, Stark and Vedres's work: recognizing that teams containing multiple individuals who themselves belong to more than a single community of practice can generate sufficient trust among group members to enable sustained collaboration across very different research traditions. Overlapping membership of multiple individuals in more than one group provides the glue (trust) that can encourage the different communities of practice to work together despite their diversity. Breakthrough innovation requires this type of "generative tension"- brought about by diversity and held in place by trust. ${ }^{161}$

De Vaan, Stark, and Vedres call this network structure a "structural fold" between overlapping groups. ${ }^{162}$ To explain how "structural folds" lead to innovation, the authors use a helpful linguistic analogy: imagine you are speaking with someone who has the exact same knowledge base as you. You would understand each other perfectly but would learn nothing new. To gain knowledge, you need to speak with someone whose knowledge base is sufficiently different from yours, but to understand each other, you have to be willing to work through misunderstandings and develop a new shared language. As the authors explain:

Structural folding matters because it does not simply facilitate a translation from one code to another but fosters the emergence of the primitive lexicon for new languages. That is, structural folding is the agent space for developing creole. Working within communities and sometimes acting in concert with others who are with them at the overlap, the structural fold makes it possible to develop a rudimentary language. Where cognitive distance is great, even a primitive lexicon can be an opportune starting point for a truly creative innovation. Together with trust, it can create a setting in which actors can cope with ambiguity and the tensions of non-translatability. ${ }^{163}$

159. Vedres \& Stark, supra note 29 , at 1151

160. Vedres \& Stark, supra note 29, at 1158.

161. De Vaan, Vedres \& Stark, supra note 154, at 1153 ("And the more distant the groups within the team, the more trust matters in regards to the tension-not for eliminating it but for holding it in place until new kinds of creatively stylistic combinations can emerge.").

162. Infra Figure 4.

163. De Vaan, Vedres \& Stark, supra note 154, at 1153. 
Brokerage and closure

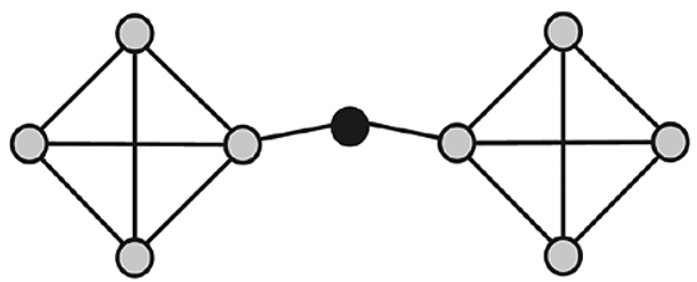

Structural hole
Intercohesion

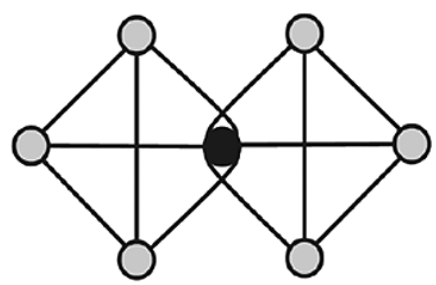

Structural fold

Figure 4: Structural Holes vs. Structural Folds

I have characterized the Kadison-Singer problem, and its successful solution by a team of computer scientists, as an example of brokerage. Nevertheless, the emerging collaboration between mathematicians and computer scientists to understand the intricacies of both the different formulations of the Kadison-Singer problem, as well as its full solution and potential applications, also helps to illustrate the importance of structural folding. Daniel Spielman, the computer scientist who led the team that provided a solution to the problem, admitted he didn't "understand really the Kadison-Singer problem" 164 as initially formulated in the language of mathematical physics. On their end, mathematicians have similarly noted that they "had a lot of trouble understanding how [the computer scientists] solved [the Kadison Singer problem]." 165 Current efforts to bring mathematicians and computer scientists together around the KadisonSinger problem are akin to efforts to build a structural fold, creating the space for a new shared language to emerge between these two groups.

\section{Problem Finding and Problem Framing in BreAKTHROUGH INNOVATION}

As de Vaan, Stark, and Vedres emphasize, a crucial step in idea generation-but one that is underappreciated in both patent law doctrine and theory-is problem finding and problem framing. ${ }^{166}$ In fact, the importance of structural folds lies precisely in the ability of overlapping groups to recombine their knowledge bases to both re-frame existing problems and formulate new problems at the intersection of multiple communities of practice. ${ }^{167}$ The importance of "problem finding" and "problem framing" to innovation was eloquently described by John Dewey, the founder of the pragmatist school of philosophy, who criticized popular conceptions of innovation as analytical problem-solving. Instead, Dewey posited:

164. Daniel Spielman, The Solution of the Kadison-Singer Problem, TechTalks.tv, http://techtalks.tv/talks/the-solution-of-the-kadison-singer-problem/59383 [https://perma .cc/L6MJ-3S9J] (navigate to 1:22).

165. Klarreich, supra note 15.

166. De Vaan, Vedres \& Stark, supra note 154 , at $1154,1186$.

167. De Vaan, Vedres \& Stark, supra note 154, at 1154, 1186. 
[I]t is artificial, so far as thinking is concerned, to start with a readymade problem, a problem made out of whole cloth or arising out of a vacuum. In reality such a "problem" is simply an assigned task. There is not at first a situation and a problem, much less just a problem and no situation. There is a troubled, perplexed, trying situation, where the difficulty is, as it were, spread throughout the entire situation, infecting it as a whole. If we knew just what the difficulty was and where it lay, the job of reflection would be much easier than it is. ... In fact, we know what the problem exactly is simultaneously with finding a way out and getting it resolved. ${ }^{168}$

Dewey's description of the "troubled, perplexed, trying situation"169 that often faces innovators can be best understood by reference to the observation - made subsequently by several sociologists of innovationthat often, the bottleneck (or "rate-limiting"170) step in a particular innovation is finding and framing a problem to be solved. Once a problem is defined, the steps to its solution frequently reveal themselves. Viewed in this way, to think about innovation as beginning with an idea and ending with product development is to overlook the most important steps that lead to idea-generation: finding and framing the problem that a particular idea is attempting to solve. Prioritizing problem-solving over problemfinding overlooks a key question: how do communities of practice find and define good problems to be solved?

Once again, the Kadison-Singer problem presents a good illustration of the importance of both problem-finding and problem-framing. The formulation of the Kadison-Singer problem itself (an example of "problem finding"), carried out by two mathematicians who were deeply interested in quantum physics, enabled the creation of an entire field of inquiry. ${ }^{171}$ Attempting to solve the Kadison-Singer problem gave rise to a myriad of innovations, first in mathematics, and then in engineering and computer science. ${ }^{172}$ In turn, the reformulation of the Kadison-Singer problem as a computer science problem is an example of the importance of problemframing. By translating the mathematically-worded Kadison-Singer problem to the language of computer science (a sparsification problem about

168. John Dewey, Analysis of Reflective Thinking (1933), reprinted in 8 The Later Works of John Dewey 201 (Jo Ann Boydston et al. eds., 2008).

169. Id.

170. Throughout this article, I use the term "rate-limiting" step to denote the step in innovation that is the slowest, and thus determinative of the overall speed with which innovation happens. The term was used originally in chemistry, but innovation policy scholars have begun to use it as applied to steps in the innovation process. See, e.g., Nancy S. Sung \& John E. Burris, Regulatory Science Innovation: A Rate-Limiting Step in Translation, 4 ScI. Trans. Med. Sept. 5, 2012, at 1.

171. Klarreich, supra note 15, at 2-6.

172. See, e.g., Casazza \& Tremain, supra note 14; Klarreich, supra note 15; Mackenzie, supra note 19; Kadison-Singer Math Solution May Mean A Boost For Science 2.0, SCIENCE 2.0 BLOG (Jul. 12, 2014, 12:30 PM), http://www.science20.com/news_articles/kadisonsinger_ math_solution_may_mean_a_boost_for_science_20-140452 [https://perma.cc/HFE4UVUJ]; Holly Lauridsen, Effort to Model Facebook Yields Key to Famous Math Problem (and a Prize), YAle News (July 7, 2014), http://news.yale.edu/2014/07/07/effort-model-face book-yields-key-famous-math-problem-and-prize [https://perma.cc/E9BY-VF7J]. 
connections in a network), Daniel Spielman made the problem amenable to analysis by a completely different set of tools than what mathematicians and engineers had employed until then. ${ }^{173}$ Note how the framing of the Kadison-Singer problem in the language of network sparsification itself suggested a solution-or at the very least suggested a set of tools and steps that should be used to address it. ${ }^{174}$ In fact, once he formulated the problem in network sparsification terms, Spielman felt confident he could solve it relatively quickly because this formulation "seemed so natural, so central to the kinds of things [he thought] about."175

Problem-framing, as I use the term in this Article, is closely related to problem-finding. To find a problem involves "framing" a puzzle about the world in a way that can be analytically tackled. I use problem-finding to denote the first "formulation" or "framing" of such a puzzle or question to be solved, while I reserve the term "problem-framing" to reformulations of the equivalent problem in a language that can be understood by additional communities of practice. As the Kadison-Singer problem illustrates, often truly innovative ideas begin with "a fresh conceptualization of the problem itself." 176

The concept of structural folds provides a way to think about how new problems are identified and then successively re-framed. It is precisely through the friction or "generative tension" of multiple communities with diverse cognitive repertoires that come together at structural folds that new problems are found. ${ }^{177}$ Sociologists Richard Lester and Michael Piore have called the process of finding a new problem "interpretation" (as opposed to the "analysis" that takes place to solve an already well-defined problem). ${ }^{178}$ Much like de Vaan, Stark, and Vedres, Lester and Piore compare the process of problem finding to what takes place when two different linguistic communities first meet and attempt to understand each other. ${ }^{179}$ In their study of innovation in three different industriesblue jeans, cellular telephones, and medical devices-Lester and Piore conclude: "The way that ... problems came to be identified and clarified to the point where a solution could be discussed was through conversations among people from different backgrounds and with different perspectives ... . [W] hat emerges from these conversations, if they are sustained, is something very much a language community. New products emerge out of that community." 180 Sustaining these conversations in the

173. See Klarreich, supra note 15 , at 1.

174. Klarreich, supra note 15 , at 1 .

175. Klarreich, supra note 15 , at 1.

176. Vedres \& Stark, supra note 29, at 1151.

177. See David Stark, The Sense of Dissonance 109 (2009) (arguing that while "[w]ell-defined problems can be solved with the firm's accumulated knowledge, ... the real challenge of innovation is less to solve already identified problems than to anticipate and generate new problems").

178. Richard Lester \& Michael Piore, Innovation: The Missing Dimension 53 (2006).

179. Id. at $53-54$.

180. Id. at $10-11,51$. Lester and Piore describe how three key technologies emerged from boundary-crossing innovation: "Cellular telephones are the marriage of the radio and 
face of initial misunderstandings and ambiguities created the necessary "generative tension" - using de Vaan, Stark, and Vedres' terminologythat led to breakthrough innovation. ${ }^{181}$

Yet, problem finding is fraught with obstacles arising from the difficulty of communicating or translating knowledge across communities of practice-in other words, arising from the very information-flow difficulties inherent in the architecture of knowledge space and described in detail earlier in this Part. ${ }^{182}$ Thus, investigating the origin of good ideas brings us back full circle to incorrect assumptions about the free flow of information. It is only by understanding the social failures that lead to the breakdown in cooperation across communities (or that prevent cooperation from arising in the first place) that we can begin to develop policy initiatives to optimize innovation outcomes.

\section{Summary}

Harnessing studies in the sociology of networks, this Part described how the "lumpy" structure of knowledge networks-characterized by communities of practice with dense social relationships separated by structural holes-prevents the free flow of potentially complementary information across community lines. Hurdles to information flow-or more precisely to information exchange, recombination, and reformulationacross structural holes prevent or delay the emergence of breakthrough innovation. This is because breakthrough ideas, spurred by the identification and framing of new problems, emerge at structural folds: sites in the knowledge network where cognitively distant communities of practice interact with each other.

Disrupting the assumptions made in market failure models of innovation that information flows freely across the knowledge space, and that a ready set of problems to be solved is "out there," reveals the importance of social structures for both information flow and its productive recombination. Therefore, understanding structural holes, as well as how they arise and are maintained, is a crucial task in innovation policy. The next Part undertakes this task through three case studies in three different industries-computer science and mathematics, public health, and medical research. The case studies serve two functions: first, they make more con-

the telephone; fashion jeans bring together traditional workmen's clothing and laundry technology borrowed from hospitals and hotels; medical devices draw on both basic life sciences and clinical practice. Without integration across the borders separating these different fields, there would have been no new products at all." Id. at 14-15.

181. Id. at 54 (describing how "[t]he cell phone emerged in the space created by the ambiguity about whether the product was a radio or a telephone; by playing with that ambiguity, the device became something that was different from either of them").

182. See supra Part II.A. See also Lester \& Piore, supra note 178, at 33 (describing the reluctance of managers and engineers to work across boundaries: "For all the talk about integration across boundaries in the literature and in our interviews, our respondents were much more comfortable with - and much better at talking about-a world in which boundaries were well defined and well policed than a world in which communication was free and open."). 
crete the abstract propositions of network studies, illustrating the ubiquity of social barriers to innovation; second, they contribute to network research itself by proposing a taxonomy of what I term "social network failures"-characteristics of the social network fabric that prevent fruitful transmission and recombination of ideas through structural folds by keeping structural holes in place.

Understanding, through specific case studies, how different barriers to information flow and problem-finding/framing emerge helps identify areas where patent law doctrine is out of step with how scientific and technical research actually takes place in the laboratory, and provides a guide to better align patent doctrine with the realities of scientific and technical research. I analyze these implications for patent doctrine in Part IV. More broadly, understanding why and how productive structural folds fail to form or fail to be maintained is as important to the design of innovation law and policy as is understanding why and how markets fail to optimally sustain innovation. I take up these implications in Part VI.

\section{SOCIAL NETWORK FAILURES IN INNOVATION: THREE CASE STUDIES}

This Part presents three case studies that illustrate the importance of social structure for both information flow and its productive recombination in a variety of industries. These examples provide concrete evidence that, rather than flow freely, information spreads very unevenly across communities of practice-due to a variety of social barriers. They also show how problem-finding and problem-framing are key rate-limiting steps in the formulation of breakthrough ideas-steps that deserve more attention from a law and policy perspective. Through these case studies, I develop a taxonomy of social network failures. The taxonomy (Figure 5) complements traditional market failure analyses of innovation long used by law and economics scholars (and depicted in Figure 1) by identifying specific social barriers to innovation that can guide new law and policy interventions.

\section{A. Social Network Failures in Public Health: Light Cigarettes And CANCer}

This first case study concerns a social network failure in public health resulting in a ten-year delay in the discovery that smoking low-tar or "light" cigarettes was just as carcinogenic as smoking regular cigarettes. Following the widespread recognition of smoking as the leading cause of lung cancer in the late 1960s, tobacco companies began focusing their efforts on manufacturing "light" cigarettes. ${ }^{183}$ Public health experts initially believed that light cigarettes would decrease cancer risk-based on the

183. See U.S. Dep't of Health, Educ., and Welfare, Public Health Service Publication No. 1103, Smoking and Health: Report of the Advisory Committee to the Surgeon General of the Public Health Service (1964). 
plausible assumption that "cigarettes that delivered less tar to smokers would be likely to produce less cancer as well." 184 Consumption of light cigarettes increased dramatically in the 1970s and 80 s, driven by consumers' informed belief that light cigarettes were a much safer choice than unfiltered ones. ${ }^{185}$

It is now widely accepted, however, that light cigarettes are no less carcinogenic than regular cigarettes, and can even lead to particularly aggressive forms of cancer. ${ }^{186}$ Empirical data required to reach this conclusion, however, was publicly available ${ }^{187}$ a full decade before public health researchers actually made this important finding. ${ }^{188}$ But crucial empirical data, while nominally public as published research papers, was distributed across research communities that did not collaborate or communicate with each other and were unaware of each other's findings despite all being concerned with studying the same topic: cancer and smoking. ${ }^{189}$ In fact, the three different research communities in question-epidemiologists, smoking laboratories, and chemists focusing on cigarette reverse engineering - had received over US\$200 million of funding from the National Cancer Institute (NCI) to conduct research on the effects of cigarette smoking.

Epidemiologists doing large population studies had identified a more aggressive form of lung cancer, whose incidence was rising. ${ }^{190}$ The rates of this more aggressive lung cancer began to rise shortly after the introduction of light cigarettes in the market, but epidemiologists did not make the connection between light cigarette smoking and this more aggressive form of lung cancer. ${ }^{191}$ At around the same time, smoking labo-

184. U.S. Dep't of Health \& Human Servs., Risks Associated with Smoking Cigarettes with Low Machine-Measured Yields of Tar and Nicotine 1-2 (2001) ("Faced with the continuing exposure of large numbers of smokers to the cancer-causing substances in tobacco smoke, public health authorities made the valid conclusion that cigarettes that delivered less tar to smokers would be likely to produce less cancer as well, and the effort to produce and market low-tar cigarettes began to gather momentum.") (citation omitted).

185. Id. at 197 ("To a considerable extent, smokers choose Light and Ultra-Light brands because they think that these cigarettes are not as harmful and cause fewer health problems.").

186. Id. at 146

187. I focus here on public data available to public health researchers. There are credible reports that tobacco companies themselves knew of the negative effects of low-tar cigarettes before data necessary to reach that conclusion was publicly available. See, e.g., STAFF of H.R. Comm. On Gov't Reform, 108th Cong., The Lessons of "Light" and "Low Tar" Cigarettes: Without Effective Regulation, "Reduced Risk" Tobacco Products Threaten the Public Health ii (Comm. Print 2003) ("Even as their advertisements promoted 'light' and 'low tar' cigarettes as better for health, tobacco companies knew that smokers generally received the same amount of nicotine and other toxins from these products as from their regular cigarettes.").

188. See, e.g., Noshir Contractor, Collaborative Research: Social Networking Tools to Enable Collaboration in the Tobacco Surveillance, Epidemiology, and Evaluation Network (TSEEN), Nat'l SCI. Found., Award Abstract No. 0836262, https://www.nsf.gov/ awardsearch/showAward?AWD_ID=0836262 [https://perma.cc/RE4W-E3JR].

189. Id.

190. Id.

191. Id. 
ratories studying the behavior of smokers who switched to light cigarettes discovered that this population compensated for the lower levels of tar and nicotine in light cigarettes by inhaling more deeply and smoking more cigarettes per day. ${ }^{192}$ As a result, and despite reduced machinemeasured tar yields for light cigarettes, smokers who switched to light cigarettes "preserve[d] their moment-to-moment and daily intake of nicotine." 193 Finally, cigarette reverse engineering laboratories identified new additives in light cigarettes with unknown carcinogenic properties. ${ }^{194}$ These laboratories, however, remained unaware of the new type of lung cancer identified through epidemiological research, and thus did not link its rising incidence to these potential carcinogens in light cigarettes. ${ }^{195}$

It was not until a researcher at the University of California San Francisco, Neal Benowitz, came across research in all three areas that a promising hypothesis could be formulated-linking the new potentially carcinogenic additives in low-tar cigarettes and the behavior of light cigarette smokers with the new, more aggressive type of lung cancer. ${ }^{196} \mathrm{Be}$ nowitz convinced the NCI to fund research to test this hypothesis. In six months, a team of researchers from all three fields funded by the NCI showed this hypothesis to be correct-and ten years of research was finally connected. ${ }^{197}$

This case study quite strikingly illustrates how important information to address a public health concern, which was located "out there" in the public domain, free of legal encumberments, and accessible to anyone who wanted to find it, nevertheless was not in fact accessed or productively recombined by relevant actors for a ten-year period. To the contrary, when knowledge resources reside in different communities of practice that are separated by a structural hole, making information "free" or "open" is often insufficient to solve complex problems requiring their combined community expertise. The barrier to information recombination in this case was neither private control of information, nor high access costs-at least not in the sense that "access costs" are conceptualized in the open source literature as a function of technological accessibil-

192. U.S. Dep't of Health \& Human Servs., supra note 184, at 3.

193. U.S. Dep't of Health \& Human Servs., supra note 184, at 2.

194. U.S. Dep't of Health \& Human Servs., supra note 184, at 160. Smoking laboratories had also found that people who smoke light cigarettes can inhale up to five times as much smoke as those who smoke regular cigarettes, but these laboratories were also unaware of the epidemiological findings. U.S. Dep't of Health \& Human Servs., supra note 184 , at $18-19$.

195. See Contractor, supra note 188.

196. University of California, San Francisco, Neal Benowitz, MD, UCSF ProfiLes, http://profiles.ucsf.edu/neal.benowitz\#toc-id2 [https://perma.cc/76GB-LPKQ]; see U.S. Dep't of Health \& Human Servs., supra note 184, at 44-45, 47.

197. See Melinda T. Willis, Light Cigarettes Are Not Safer, ABC News ("This report is one that has brought together scientists of various disciplines and has concluded that there are significant health risks from switching to low-tar, light cigarettes") (quoting Scott Leischow, chief of the National Cancer Institute Tobacco Control Research Branch), http:// abcnews.go.com/Health/story?id=117102 [https://perma.cc/6RPF-T88P] (last visited Mar. $23,2017)$. 
ity and cost. ${ }^{198}$ Rather the lack of social and cognitive ties between these three communities was responsible for the ten-year delay. ${ }^{199}$

This first type of social barrier to knowledge recombination flows directly from Burt's studies on structural holes in the information space: how a community member searches for information and prioritizes information found is deeply informed by whom she knows (a social tie) and what those connections know (a cognitive tie). ${ }^{200}$ Epidemiologists were simply not keeping up to date with research in cigarette reverse engineering laboratories, neither did they interact routinely with members of that community. Similarly, chemists in reverse engineering laboratories did not routinely read epidemiological research, nor were they in regular contact with epidemiologists working on cancer. Both groups could, however, understand each other's research papers and results.

It was precisely the recognition of this deficit through NCI's experience with light cigarettes and cancer research that led to the creation of the Tobacco Informatics Grid (TobIG) - to enable collaboration within the Tobacco Surveillance, Epidemiology, and Evaluation Network (TSEEN). ${ }^{201}$ One way to think about TobIG is as a policy solution aimed at creating the infrastructure to facilitate deeper interactions and connections among communities separated by a structural hole. As we shall see in Part V, creating knowledge infrastructures is one policy initiative that can help bridge structural holes, especially when the social barrier at issue is simply a lack of social and cognitive ties between communities.

This case study also provides further evidence of the importance of problem-finding in innovation. Much like Gil Kalai's role in solving the Kadison-Singer problem, Benowitz acted as a "broker" or "boundaryspanner" between these disconnected communities. In other words, Benowitz filled a structural hole that divided the information space occupied by these three communities of practice. Note how Benowitz's role, however, was not simply one of migrating information from one community to another. His position in a structural hole, with access to knowledge from the three disconnected communities, allowed him to formulate a novel hypothesis about light cigarette smoking. In the language I have employed in this Article, Benowitz found a problem-why did cancer rates for an aggressive form of lung cancer increase following the introduction of light cigarettes to the market?- that only the combined expertise of all three communities could answer. Much like the Kadison-Singer problem, however, the rate-limiting step was problem-finding and framing. Once the problem was identified and framed, a solution emerged quite rapidly.

198. See supra Part I.A.

199. See Figure 5.

200. See supra Part II.A.

201. See, e.g., Scott J. Leischow, Allan Best, William M. Trochim, Pamela I. Clark, Richard S. Gallagher, Stephen E. Marcus \& Eva Matthews, Systems Thinking to Improve the Public's Health, 35 Am. J. Prev. Med. S196, S199 (2008). 


\section{B. Social Network Failures in Mathematics/Computer Science: The Kadison-Singer Problem}

A precise description of the Kadison-Singer problem, as a review article has remarked, "almost defies translation into simple English."202 But I have chosen it as a case study of social network failures in innovation because the path to its solution provides a powerful illustration of three important points. First, there are many sub-communities of practice within any given technological area of inquiry that-contrary to what those outside that technological area may believe-are separated by structural holes. In other words, much like the communities involved in tobacco research and described in the preceding section, these sub-communities lack socio-cognitive ties. As a consequence, they do not routinely communicate with each other and are often unaware of each other's research results. Second, in some cases, research communities within a particular technological area cannot even interpret and evaluate each other's research results: they are separated by great cognitive distances that can prevent fruitful idea recombination. ${ }^{203}$ Third, it is precisely because of the barriers generated by cognitive distance that problem framing in a language that can be understood by multiple communities is often a ratelimiting step in complex innovation. In turn, problem-framing frequently requires the creation of cross-cutting teams (or structural folds) that can develop a creole to jointly frame problems at their intersection.

To illustrate these three points, the next paragraphs provide a fuller description of the Kadison-Singer problem and efforts to address it by multiple communities of practice both within and outside the disciplinary field of mathematics. The first relevant community of practice implicated in the Kadison-Singer problem is that of quantum physics. ${ }^{204}$ The problem has its roots in Heisenberg's famous uncertainty principle, which states that it is impossible to simultaneously measure in an experiment the position and momentum of a particle. ${ }^{205}$ Heisenberg's uncertainty principle gives rise to an experimental conundrum: if position and momentum cannot be simultaneously measured, how do we describe the unique state of a particle (or of a system with multiple particles) in a way that can be experimentally verified? ${ }^{206}$ In 1930 physicist Paul Dirac postulated that "even if there is this uncertainty principle, there is always a way to get around it," 207 so that "every physical system can be [fully] described in terms of quantities which can be measured simultaneously."208 Richard Kadison and Isadore Singer, two mathematicians, wanted to figure out if there was a rigorous mathematical proof for

202. Mackenzie, supra note 19.

203. Infra Figure 5.

204. Mackenzie, supra note 19; see also Klarreich, supra note 15, at 2-6.

205. For a concise explanation of the Kadison-Singer problem, see Srivastava, supra note 16 (video tutorial).

206. Srivastava, supra note 16, at 00:15.

207. Srivastava, supra note 16, at 00:40.

208. Srivastava, supra note 16, at 00:28. 
Dirac's claim. ${ }^{209}$ In the words that I used to describe the problem in the introduction: is there mathematical proof that "every physical system can be completely described by quantities which can be measured simultaneously"? 210 Kadison and Singer thought the answer was no-but could not arrive at a mathematical proof. ${ }^{211}$ (It turns out that the answer as shown by Marcus, Spielman, and Srivastava is "yes."). ${ }^{212}$ The applications of solving Kadison-Singer are far-reaching, including improving signalprocessing for any engineering applications and an improved ability to model interactions among groups within complex networks. ${ }^{213}$

How the Kadison-Singer problem made its way from its original formulation in 1959 in the operator algebra community ${ }^{214}$ to other fields within mathematics, then engineering, and finally computer science, is a fascinating study in idea diffusion, reframing, and recombination-and in the social barriers that work against this process. In the words of a reviewer, "[i]n its original formulation, the problem was of great interest to specialists in operator algebras, but rather inaccessible to anyone else." 215 But in the 1970s, different versions (or "framings") of the Kadison-Singer problem began to emerge in other mathematical subfields, under different names: the "Paving conjecture," 216 the "Bourgain-Tzafriri conjecture," 217 the "Feichtinger conjecture." 218 The mathematicians who formulated these different versions, however, "were not always aware of each other" or of the Kadison-Singer formulation itself. ${ }^{219}$

It wasn't until 2006 that an applied mathematician and engineer, Peter Casazza, with three other mathematicians, "collected" all of these mathematical formulations in a single article. Casazza explained:

We didn't start out looking for equivalent versions of KadisonSinger. ... . We were actually trying to solve the problem, and kept moving to different areas of research [in mathematics and engineering] hoping that one of them had deep enough results to handle the problem. It was a fluke that each time we entered a new area of research, this was equivalent to their most famous unsolved problem. ${ }^{220}$

The evolution of the Kadison-Singer problem up to this point illustrates the existence of two distinct types of social barriers to the flow of information and its productive recombination, across subcommunities in

209. Srivastava, supra note 16 , at 00:49.

210. Srivastava, supra note 16, at 00:28.

211. Srivastava, supra note 16 , at 00:49.

212. Srivastava, supra note 16, at 01:10, 01:40.

213. See, e.g., Casazza \& Tremain, supra note 14, at 1; Kadison-Singer Math Solution May Mean A Boost For Science 2.0, supra note 172, at 1-2; Klarreich, supra note 15, at 5; Lauridsen, supra note 172; Mackenzie, supra note 19.

214. This community encompasses the (smaller) $C^{*}$ algebra community.

215. Mackenzie, supra note 19.

216. Mackenzie, supra note 19.

217. Mackenzie, supra note 19.

218. Mackenzie, supra note 19.

219. Mackenzie, supra note 19.

220. Mackenzie, supra note 19; see also Casazza \& Tremain, supra note 14. 
mathematics. First, much like the three communities involved in tobacco and cancer research, different mathematics communities lacked sociocognitive ties. Thus, $C^{*}$ algebra community members did not routinely interact with members of, for example, complex analysis or graph theory communities (social ties) and were thus unaware of what each other were working on (cognitive ties). But there was a second barrier that divided these communities: they did not possess the background knowledge necessary to understand each other's research results or, in the language that I use in this Article, they were separated by large cognitive distances. ${ }^{221}$ Taken together, these two factors explain the initial isolation of the Kadison-Singer problem in the $\mathrm{C}^{*}$ algebra community and the subsequent independent re-framing of the problem in different community languages.

Much like Neal Benowitz in the case of tobacco research, Peter Casazza and Janet Tremain acted as brokers. Their journal article connecting together multiple problems in different mathematical and engineering fields to the Kadison-Singer problem is an example of the power of problem-framing in pointing the way to a solution. ${ }^{222}$ Casazza and Tremain's article identified one particular framing of the Kadison-Singer problem in the language of linear algebra matrices that was "simpler to state." 223 The article served as a nexus that connected multiple understandings of the problem. As an analyst has described it, emphasizing the importance of problem framing: "almost imperceptibly, . . . the river was approaching its destination-the conjecture was becoming simpler to state, if not to prove." 224 It turns out that once the correct framing was found, a solution came relatively rapidly.

The solution to the Kadison-Singer problem did not emerge from any of these mathematical subcommunities, however. It emerged out of work on complex online networks. Daniel Spielman's laboratory-which ultimately provided the final mathematical proof that the answer to the Kadison-Singer problem was "yes"-focused on modelling "complex online communities like Facebook, hoping to gain insight into how they form and interact." 225 In essence, Spielman's research was focused on whether any given dense graph (or network, such as Facebook) could be reduced to an equivalent but sparser (and thus simpler) graph. ${ }^{226}$ Replacing dense networks with their sparse equivalents makes it much easier to run applications or perform operation on the dense network platform. In technical terms, this area of research is called "graph sparsification."227

It turns out that the Kadison-Singer problem about whether physical systems can be fully described only through quantities that can be mea-

221. Infra Figure 5.

222. See Casazza \& Tremain, supra note 14, at 4.

223. Mackenzie, supra note 19.

224. Mackenzie, supra note 19 (emphasis added).

225. Lauridsen, supra note 172.

226. See Srivastava, supra note 16.

227. Mackenzie, supra note 19. 
sured simultaneously, and the computer science question of whether any complex network can be sparsified into a simpler one, can be framed as the same question about matrices and linear algebra. It was mathematician Gil Kalai who first made this connection when discussing Spielman's research in sparsification-another instance of brokerage, this time between the operator algebra community and computer science. ${ }^{228}$ Once these two problems were connected and framed as addressing the same question, Spielman's laboratory was able to provide a proof in a relatively short period of time (five years) using computer simulation tools that the mathematics community is still assimilating. 229 The proof has also brought together groups of computer scientists and mathematicians to develop a shared language to address the myriad implications of solving the Kadison-Singer problem-in effect seeking to create a structural fold where new recombinations can take place. 230

The migration of the Kadison-Singer problem from the mathematics community to that of computer science further demonstrate the crucial, rate-limiting step of problem framing in innovation. It also shows how large cognitive distances between two or more communities of practice can delay the solution of problems that lie at their intersection. In this case, Spielman himself has professed to not understanding the original Kadison-Singer framing of the problem. On their end, several mathematicians have called Marcus, Spielman and Srivastava's proof "magical," and are still struggling to understand the tools that this team of computer scientists used to solve the Kadison-Singer problem. ${ }^{231}$

\section{Social Network Failures in Medical Care: Fertility in CANCer Patients}

This final case study emerges from interviews that I conducted with members of the Oncofertility consortium - an interdisciplinary team of oncologists, endocrinologists, cryobiologists and engineers researching fertility preservation techniques for young cancer patients. ${ }^{232}$ This case study is part of a long-term, broader comparative project to study the

228. Klarreich, supra note 15.

229. Klarreich, supra note 15.

230. See Klarreich, supra note 15.

231. See, e.g., Klarreich, supra note 15 ("We don't have the manual for this magic tool yet." (quoting mathematician Terence Tao)); Orr Shalit, Another One Bites the Dust (Actually Many of Them), Noncommutative Analysis (June 20, 2013), https://noncommutativeanalysis.wordpress.com/2013/06/20/another-one-bites-the-dust-actually-many-of-them [https://perma.cc/S5DV-LZXK] ("[T] he proof looks completely magical to me."). In his blog, Shalitt also discussed the difficulties, from a mathematician's perspective, of fully understanding the techniques used by Marcus, Spielman, and Srivastava: "Contrary to what I hopefully wrote above, there is no chance I will be able to do something with their techniques. There is a very big difference between somehow following a proof, and actually understanding how the techniques work and where to apply them." Id.

232. Interdisciplinary Research Program Consortia, Nat'L Insts. of Health (June 25, 2014), https://commonfund.nih.gov/Interdisciplinary/consortia [https://perma.cc/BJ9UJSSK]; The Oncofertility Consortium: Fertility Preservation for Women, NAT'L Insts. OF HeALth (June 25, 2014), https://commonfund.nih.gov/Interdisciplinary/consortia/oncofer [https://perma.cc/RE98-NTP4]. 
formation and functioning of interdisciplinary teams across different technological domains. ${ }^{233}$ For the purpose of this Article, this case study helps illustrate and identify a separate set of social barriers to productive problem-finding and information-recombination across community boundaries: different ways of evaluating the worth of research projects, research tools, and research results-what I call different evaluative frames. As was the case in the previous two case studies, interviews with Oncofertility consortium members also show that problem-finding and problem-framing at the intersection of multiple communities to be a key step in the generation of ideas for complex innovation.

The Oncofertility consortium was funded as part of a National Institutes of Health (NIH) Roadmap Initiative. ${ }^{234}$ This initiative launched in 2003 with the goal of identifying (and funding) potentially transformative research requiring collaboration and coordination across NIH institutes and across traditional scientific disciplines. ${ }^{235}$ The goal of the Oncofertility consortium was to address the unmet need of cancer survivors (and in particular female survivors) for fertility preservation options at the time of diagnosis. As cancer treatments have become more sophisticated and effective, the number of cancer survivors-and in particular childhood cancer survivors - has increased worldwide. ${ }^{236}$ But research on the impact of cancer therapeutics on male and female fertility, as well as research on fertility preservation techniques for females, has lagged behind. So has the availability of fertility services for newly diagnosed cancer patients: at the time of the grant, the infertility industry was structured to deal exclusively with planned in-vitro fertilizations but not equipped to offer emergency procedures. And despite the rising numbers of patients living cancer-free, treating oncologists seldom discussed the treatment's effect on fertility, or options for fertility preservation, with their patients. ${ }^{237}$ This was the case despite studies showing that cancer patients rank fears of losing their fertility second only to those of facing death. ${ }^{238}$

233. For a full description of the methodology used in this case study and a more detailed account of the Oncofertility consortium, see Laura G. Pedraza-Fariña, Constructing Interdisciplinary Collaboration: The Oncofertility Consortium as an Emerging Knowledge Commons, in Governing Medical Knowledge Commons (Brett Frischmann, Michael Madison \& Katherine Strandburg, eds., forthcoming 2017, Cambridge Univ. Press).

234. Elias A. Zerhouni, US Biomedical Research: Basic, Translational, and Clinical Sciences, 294 JAMA 1352, 1355 (2005).

235. Elias A. Zerhouni, The NIH Roadmap, 302 Science 63, 63 (2003).

236. Nat'l Cancer Inst., SEER Cancer Statistics Review, 1997-1999 11-12 (L.A.G. Reis et al. eds., 2002), https://seer.cancer.gov/archive/csr/1973_1999/overview.pdf [https://perma.cc/8HGD-EXN8].

237. Teresa K. Woodruff, The Emergence of a New Interdiscipline: Oncofertility, in Oncofertility: Fertility Preservation for Cancer Survivors 3, 7 (Teresa K. Woodruff \& Karrie Ann Snyder, eds., 2007).

238. See Carrie L. Nieman, Karen E. Kinahan, Susan E. Yount, Sarah K. Rosenbloom, Kathleen J. Yost, Elizabeth A. Hahn, Timothy Volpe, Kimberley J. Dilley, Laurie Zoloth \& Teresa K. Woodruff, Fertility Preservation and Adolescent Cancer Patients: Lessons from Adult Survivors of Childhood Cancer and Their Parents, 138 Cancer Treat Res. 201, 205 (2007). 
As a result, many cancer survivors were confronted with a second devastating diagnosis: that of infertility resulting from their cancer treatments.

One fundamental reason for this disconnect between the needs of cancer patients and research and treatment priorities of the research and medical community that emerged from my interviews was the lack of communication and collaboration between oncologists and reproductive endocrinologists. The oncofertility consortium sought to remedy these "information, data, and option gaps" 239 and "serve as an authoritative voice for research, clinical practice, and training at the intersection of oncology, pediatrics, reproductive science and medicine, biomechanics, material science, mathematics, social science, bioethics, religion, policy research, reproductive health law, cognitive and learning science in a new discipline called oncofertility." 240

One particular barrier to collaboration between oncologists and endocrinologists represents a common thread across all interviewees: the different evaluative frames in these two communities to judge the worth of a particular line of research or treatment. These different ways of evaluating the worth of a research project or of research results led to different research priorities and practice styles that kept the two communities from working together and from working on problems at the intersection of both fields. Importantly, this barrier to collaboration was perpetuated by organizational structures, such as professional associations, university and medical school departments, and grant review boards. ${ }^{241}$

Oncologists' focus on understanding the mechanisms of cell proliferation and cell death (the hallmarks of cancer), and on improving survival rates, meant that there was scant research into the effects of cancer chemotherapeutic agents on fertility. ${ }^{242}$ Oncology research prioritized identification of cellular proliferation pathways and new genes that could constitute potential therapeutic targets. ${ }^{243}$ Research focusing on the effect of chemotherapeutic drugs on fertility was not considered mainstream oncology research: indeed, it was seldom funded by oncology

239. Woodruff, supra note 237 , at 7 . The grant application describes the unmet needs of the cancer-survivor community in these terms. The "information gap" refers to the lack of information regarding cancer treatment's effect on fertility and fertility preservation options to newly diagnosed cancer patients. The "data gap" refers to the "paucity of data on the precise gonadotoxicity of cancer drugs," and the "option gap" refers to the lack of research into fertility preservation techniques for females, including pre-pubescent girls. Woodruff, supra note 237, at 9-10.

240. Teresa K. Woodruff, Administrative Core, The Oncofertility Consortium, http://oncofertility.northwestern.edu/resources/administrative-core [https://perma.cc/ XNS4-RR8J].

241. Interview with Oncofertility Grant Principal Investigator, Basic Sciences Track, in Chicago, IL (October 8, 2014; March 13, 2015).

242. Woodruff, supra note 237, at 9 ("[M] edical oncologists are not aware of the precise reproductive threats of their treatments on reproductive outcomes and clinical reproductive endocrinologists do not routinely treat cancer patients.").

243. Telephone interview with Principal Investigator in Oncology (Mar. 10, 2015); telephone interview with Principal Investigator in Reproductive Endocrinology (Mar. 13, 2015). 
grants. ${ }^{244}$ On the clinical side, the gold standard for evaluating the success of a treatment program in clinical oncology was survival rates-a treatment's effect on fertility was often not even part of a research design. ${ }^{245}$ The perception of one Oncofertility consortium member captures what was reported by a majority of interviewees: "I find that in our area anyway the oncologists are a little bit resistant to participating in studies such as these, it's not really high on their list of priorities."246

Oncologists' research priorities developed into particular practice styles and protocols that became entrenched routines. Fertility preservation required a significant modification of these established practice routines. For example, a clinician member of the consortium remarked,

[t]here are individuals who have styles of practice. The issue for oncologists is living or dying. From the outset you see patients for cancer, the team says so and so has this cancer, and it's very hard and you don't know how much they have to live. . . . My colleagues in oncology, they are so busy and they are so much dealing with living and dying issues. How to treat the cancer, what kind of cancer is it. They are getting pulled in all different directions about taking the cancer out. Talking about fertility preservation is not in their agenda. ${ }^{247}$

The Oncofertility consortium attempted to change these entrenched practice styles by requiring treating oncologists to ask fertility-related questions before they could officially "close" their patient intake forms (and thus record a patient appointment as finished in their electronic records). Interviewees report, however, that this initiative was met with strong resistance from oncology groups.

These evaluative frames that prioritized survival rates also influenced how oncologists construed the priorities of their own patients, which did not include a focus on fertility preservation. A principal investigator with a background in endocrinology described her experience speaking with oncologists as follows: "they would tell me, we don't worry about [fertility], [the patients] should really think about that later and they are not married so they are not even thinking about that." 248 Another interviewee similarly remarked:

these physicians had in-bred biases about how to deliver care to these patients. And those biases ran again from "Don't bother her, she's got enough on her mind right now, my focus is on getting her well. Don't worry about the esoteric stuff, she can't afford this. Don't

244. Id.

245. Id.

246. 2007 Oncofertility Consortium Conference, The Oncofertility Consortium (Dec. 9, 2007), http://oncofertility.northwestern.edu/resources/npc-panel [https://perma.cc/LPZ7PC99] (navigate to endocrinology participant comment at 42:00).

247. Interview with Oncofertility Grant Principal Investigator in Clinical Practice, in Chicago, IL (Feb. 24, 2015).

248. Interview with Oncofertility Grant Principal Investigator, Basic Research track, in Chicago, IL (March 13, 2015). 
even bring it up."249

The second community, that of reproductive endocrinologists, did not routinely treat cancer patients; rather, it was used to treating generally healthy patients whose only diagnosis was infertility, and their frames for evaluating treatment success and research priorities aligned with the priorities of this subpopulation-understanding the reproductive system of otherwise healthy patients. As one Oncofertility physician remarked:

If you go into an infertility clinic, the vast majority of patients that you're gonna see in that waiting room are women, over the age of 35 , who've been trying to get pregnant for a long time and are typically very well and very healthy patients. They're dealing with infertility, which is a horrific diagnosis and it is hard to deal with, but for the most part that's their main concern. ... When we're talking about oncology, we're talking about very acutely sick patients. Sometimes, the patient's so sick that they're in-patient. ${ }^{250}$

This focus on age-related infertility led to entrenched treatment routines tailored for otherwise healthy women with an infertility diagnosis. As explained by several consortium members: "Most IVF places have a programmed and linear way of bringing people through an IVF cycle. Patients are taken through step-wise. Now we have patients who need to be shunted into IVF tomorrow afternoon. We are used to consumerdriven type of care, this group is more of an emergent-care, medically driven type of care." 251 For this reason, tailoring both research and medical care to oncology patients required a radical reorganization of the practice routines of reproductive endocrinologists:

As a fertility specialist, I'm asking you now to see a patient the same day. I don't care if you have a three-month waiting list. This patient's not waiting. You're gonna see them right now. I'm asking you to take care of a patient who might be sicker, her blood counts might be different than what you're used to seeing. I'm asking you to step outside of your comfort level of having normal healthy patients and seeing someone who is not so perfectly blood count wise normal. And make sure you're okay with that. ${ }^{252}$

How, then, did these two communities overcome their different evaluative frames and research priorities to work on a joint project that neither community prioritized? Crucially, the barriers separating the two communities not only prevented working on a common problem (fertility preservation) but also prevented the realization that there was a problem to begin with that required the joint efforts of both communities. As a principal investigator in the original grant application emphasized: "You had

249. Interview with Oncofertility Grant Administrator, in Chicago, IL (July 23, 2015).

250. Interview with Oncofertility Grant Patient Navigator, in Chicago, IL (Mar. 19, 2015).

251. Id.

252. Interview with Oncofertility Grant Patient Navigator, in Chicago, IL (Mar. 19, 2015). 
issues on both sides of the equation so it wasn't that there was a fault line. It was just that there was no conceptualization of the issues." 253 Thus, conceptualizing the need for research in what is now called the field of oncofertility is itself an example of "problem finding." As interviewees recount the process of team assembly, the original problem finding insight was a case of brokerage: the principal investigator for the Oncofertility grant, herself an endocrinologist, became the head of a cancer center and therefore had access to complementary information from both disciplines. ${ }^{254}$

During my interviews, oncofertility researchers recount many additional cases of problem finding during their joint research that emerged precisely because basic researchers from multiple disciplines (biomedical engineering, oncology, reproductive endocrinology, and primate biology) worked together to figure out a way to stimulate the growth of follicles outside the body (in vitro), and they shared their findings in monthly laboratory meetings. In other words, interviewees reported that these problems would not have been discovered (or would not have been discovered as quickly) but for the boundary-crossing interactions facilitated by the Oncofertility Consortium. Problem-finding in the context of this boundary-crossing teamwork led to what participants considered to be their most important findings.

The following passage from a researcher working with monkey ovaries vividly recounts how the team quickly came to recognize a problem with follicle growth in monkeys that could not be observed in rodents (the most popular model used in the laboratory by basic researchers) and that more closely resembled the situation in human ovaries:

What we found for example was that some of the follicles would actually just sit there and look at you. And then you had others that would grow over the five weeks and turn into these beautiful, gorgeous antral follicles. And you'd say, "What's this heterogeneity? Do you see this in the rodent?" And they [researchers working on a rodent model] would go, "No." ... Then you think, "Well, so how does this relate to follicles from humans?" We found if we took follicles from young, reproductive age monkeys-what would be considered 20 year olds in humans - they did really well, would give us a lot of those large growing follicles. If we took them from the animals, that were over 15 years of age, we didn't. . .And we thought, "Well, what did this mean for the cancer patients that's 40 or 35 as opposed to 20?" It made us think on a much broader scale and made us think that immediately because we were having these tremendous and exciting

253. Interview with Oncofertility Grant Principal Investigator, in Chicago, IL (Mar. 13, 2015).

254. Telephone interview with Principal Investigator in Oncology (Mar. 10, 2015); telephone interview with Principal Investigator in Reproductive Endocrinology (Mar. 13, 2015); telephone interview with Oncofertility Grant Administrator (Mar. 3, 2015); telephone interview with Oncofertility Grant Administrator (July 21, 2015). 
lab meetings every month. ${ }^{255}$

In other words, when working together, monkey and mouse researchers were able to discover a discrepancy in how mouse and monkey ovaries behaved when grown in culture (outside the body). It turned out that a significant portion of monkey follicles simply did not progress into mature eggs. Mouse follicles did not display this "heterogeneity." Upon further investigation (prompted only by the finding of this discrepancy), monkey researchers realized that this inability of a significant portion of monkey follicles to mature into eggs was related to the age of the monkey donor female: in young monkeys, most if not all follicles matured, but in older monkeys they did not. Because monkeys are more closely related to humans than mice, the researchers could extrapolate their findings to humans, leading to further questions and research regarding the effect of maternal age on follicle maturation in humans.

What is important to recognize is that this example of problem finding required more than a preferred network position with access to data from both fields, which could then be combined to make a new discovery (as brokerage is conceptualized in Burt's model). Rather, knowledge about new problems emerged from the regular interactions and sharing of raw data between multiple communities-it was a synergistic, emergent property of relationships across communities that happened at the structural fold created by the Oncofertility consortium.

\section{A Taxonomy of Social Network Failure}

Taken together with social network theory, these case studies allow us to answer the important yet overlooked questions posed in Part I: What does it mean in fact for information to be free of legal encumberments? How is it in fact accessed by social actors? Are there any other barriers to "accessibility"? And, switching vantage points from seeking those conditions that enable individual autonomy and creativity to those that optimize resource management, why have complex problems resisted study and treatment?

The three case studies described above show that, even if information is free of legal encumberments-unprotected by patents or trade secrets-social barriers prevent innovators from fully accessing or fully taking advantage of such nominally "free" information. How social actors in fact search for information is deeply influenced by innovators' search strategies. In turn, as illustrated by the three case studies above, these strategies are constrained by social factors: (1) lack of social-cognitive ties between communities of practice with complementary information or skills; (2) large cognitive distances between communities of practice; (3) different (and often clashing) evaluative frames leading to different re-

255. Telephone interview with Principal Investigator in Reproductive Endocrinology working with Rhesus Monkeys (Feb. 23, 2015). 
search priorities. ${ }^{256}$ Complex problems have resisted study and treatment in large part because of these difficulties in bringing together the diverse sources of knowledge that are often needed to address them. The three social factors described above make it difficult to create a structural fold where teams can work together to build trust and develop a common language that bridges large cognitive distances.

Crucially, all three case studies place problem-finding and problemframing at the center of breakthrough innovative activity. It is precisely by delaying problem-finding and problem-framing at the intersection of multiple communities of practice that these three social barriers to the flow of information delay (or block) breakthrough innovation. By treating information as free-flowing, and by conceptualizing innovation simply as the process of solving pre-existing problems, patent law theory and doctrine ignore these important insights. The next two Parts of this Article engage precisely with the implications of the insights gathered from social network theory and these case studies for patent doctrine and innovation theory more broadly.

Social Network Failure

Example

\begin{tabular}{|l|l|}
\hline Lack of social-cognitive ties & Tobacco Research \\
\hline Cognitive distance & Kadison-Singer Problem \\
\hline Different (clashing) evaluative frames & Oncofertility \\
\hline
\end{tabular}

Figure 5: A Taxonomy of Social Network Failures.

\section{IMPLICATIONS FOR PATENT LAW DOCTRINE}

The previous parts of this Article have both brought to light and challenged the twin assumptions about the nature of information flow and the origin of ideas that pervade market failure analyses of innovation. Patent law doctrine, whose development owes much to market failure analyses of innovation incentives, echoes these assumptions. By ignoring social network effects on information flow and the origin of breakthrough innovation, however, patent law's incentive structure is ultimately misaligned with how innovation happens on the ground.

Three key patentability doctrines-novelty, obviousness, and utilityare concerned with weeding out innovations that do not require a patent incentive (or for which granting a patent would lead to socially inefficient results). Novelty is codified in section 102 of the 1952 Patent Act and the America Invents Act. ${ }^{257}$ In both Acts, novelty requires an invention to be

256. See infra Figure 5.

257. Two patent acts are relevant for unexpired U.S. patents. The Leahy-Smith America Invents Act (AIA), which went into effect in 2012, covers all patents filed on or after March 16, 2013. See Pub. L. No. 112-29, 125 Stat. 285 (codified as amended in 35 U.S.C. $\$ 102(2012)$ ). The Act that the AIA replaced, the 1952 Patent Act, governs all unexpired patents filed before that date. Act of Jul. 19, 1952, Pub. L. No. 593, 66 Stat. 792. 
"new." 258 In other words, innovators cannot obtain the right to exclude others for inventions that the public already possesses, either because these inventions are in the public domain, or because they are covered by a patent granted to another inventor. ${ }^{259}$ The obviousness requirementfirst announced by the Supreme Court in Hotchkiss v. Greenwood ${ }^{260}$ and later codified in section 103 of the 1952 Patent Act and the America Invents Act $^{261}$-requires patentable inventions to show a degree of inventiveness in addition to novelty. ${ }^{262}$ In the words of the Hotchkiss Court, an invention deserving of a patent must show a "degree of skill and ingenuity [beyond that of an "ordinary mechanic"] which constitute essential elements of every invention." 263 As codified in section 103, a patent "may not be obtained ... if the differences between the claimed invention and the prior art are such that the claimed invention as a whole would have been obvious before the effective filing date of the claimed invention to a person having ordinary skill in the art ..."264 The obviousness requirement is often explained in economic terms: market pressures and market competition are likely to lead "ordinary mechanic[s]" 265 to make routine improvements to existing technology_negating the need for a patent on these "obvious" inventions. The utility requirement, codified in section 101 of the 1952 Patent Act and the America Invents Act, ${ }^{266}$ requires that an invention have a "significant" and "immediate benefit to the public."267

258. The relevant statutory language from the 1952 Act reads:

Conditions for patentability; novelty and loss of right to patent: . . . A person shall be entitled to a patent unless-(a) the invention was known or used by others in this country, or patented or described in a printed publication in this or a foreign country, before the invention thereof by the applicant for a patent.

Ch. 10, § 102, 66 Stat. 792, 797 (1952) (current version at 35 U.S.C. $§ 102$ ). The newly amended Leahy-Smith America Invents Act of 2011, 35 U.S.C. $§ 102$, reads: "Conditions for patentability; novelty: ... A person shall be entitled to a patent unless-(1) the claimed invention was patented, described in a printed publication, or in public use, on sale, or otherwise available to the public before the effective filing date of the claimed invention." $\S 102$.

259. See, e.g., Dan L. Burk \& Mark A. Lemley, Inherency, 47 WM. \& MARy L. Rev. 371, 383-84 (2005); Kevin Emerson Collins, The Knowledge/Embodiment Dichotomy, 47 U.C. Davis L. Rev. 1279, 1308-09 (2014); Joshua D. Sarnoff, Patent-Eligible Inventions After Bilski: History and Theory, 63 Hastings L. J. 53, 101-02 (2011).

260. 52 U.S. 248, 267 (1850).

261. See 35 U.S.C. $\$ 103$.

262. See, e.g., John Duffy, Inventing Invention: A Case Study of Legal Innovation, 86

Tex. L. Rev. 1, 3-4 (2007) (explaining the legal origins of the obviousness doctrine).

263. Hotchkiss, 52 U.S. at 267.

264. 35 U.S.C. $§ 103$ (explaining “[c]onditions for patentability; non-obvious subject matter").

265. Hotchkiss, 52 U.S. at 265, 267.

266. 35 U.S.C. $\$ 101$ ("Inventions patentable[:] Whoever invents or discovers any new and useful process, machine, manufacture, or composition of matter, or any new and useful improvement thereof, may obtain a patent therefor, subject to the conditions and requirements of this title.") (emphasis added).

267. In re Fisher, 421 F.3d 1365, 1371 (Fed. Cir. 2005) (quoting Nelson v. Bowler, 626 F.2d 853, 856 (C.C.P.A. 1980)) (emphasis omitted). 
Both novelty and obviousness rely on identifying a body of publicly available knowledge or "prior art" against which to assess the novelty and obviousness of the invention seeking patent protection. ${ }^{268}$ Relying on market failure models of innovation, which predict that the sum of human knowledge will be easily available to innovators to address technical problems once access costs decrease, courts have systematically widened the amount of prior art that is considered accessible to a person having ordinary skill in the art. ${ }^{269}$ And just as market failure analyses of innovation treat the origin of problems to be solved (and of those ideas that attempt to solve them) as exogenous to economic analyses of innovation, so does patent law, through its utility and obviousness doctrines, assume that problems to be solved are simply out there. ${ }^{270}$ As we have seen in the previous sections, however, in many breakthrough innovations, the bottleneck is actually problem-finding and problem-framing.

The next three sections elaborate how these twin assumptions underlie court decisions in the patentability doctrines of novelty, obviousness and utility, and make the case for correcting them.

\section{A. The Free Flow Assumption in Patent Doctrine Novelty}

Novelty appears to be a straightforward inquiry: it denies patent protection when every single element of a patent claim is present in a single piece of prior art (a single publication or a single publicly known invention). ${ }^{271}$ There is an evident reason to require that a patent be "new": there is no justification for granting a patent monopoly for an invention that the public already possesses. Because it treats the public domain as a uniform repository of information, however, the novelty doctrine does not consider the transport and repurposing of an invention from one community to another as an act of invention. Take, for example, the invention in In re Schreiber. ${ }^{272}$ The invention claimed, "A dispensing top for passing only several kernels of a popped popcorn at a time from an open-ended container filled with popped popcorn." 273 The court rejected claim one of the invention as inherently anticipated by the "Harz" Swiss patent. ${ }^{274}$ The Harz patent disclosed " 'a spout for nozzle-ready canisters,' which may be tapered inward in a conical fashion, . . . for purposes such as dispensing oil from an oil can." 275 In essence, the court reasoned that the device described in the "Harz" patent as an oil dispenser could be

268. Robert Patrick Merges \& John Fitzgerald Duffy, Patent Law and PolICY: CASEs AND Materials 337-38, 606 (LexisNexis, 6th ed. 2013).

269. See infra Part IV.A. Obviousness.

270. See infra Part IV.B. Obviousness \& Utility.

271. See, e.g., Verdegaal Bros., Inc. v. Union Oil Co. of Cal., 814 F.2d 628, 631 (Fed. Cir. 1987) (Anticipation requires that "each and every element as set forth in the claim is found, either expressly or inherently described, in a single prior art reference.").

272. 128 F.3d 1473 (Fed. Cir. 1997).

273. Id. at 1475 .

274. Id. at $1477-78$.

275. Id. at 1475 . 
repurposed to serve as a popcorn dispenser. ${ }^{276}$ But recognizing the organization of knowledge space in separate innovation communities, rather than in a uniform public domain, can raise doubts about this decision. Migrating and repurposing the oil can container may indeed constitute a "novel" public benefit. 277

Nevertheless, there is good reason from a policy perspective to conclude that considering such migrations a "new" product innovation deserving of patent protection would-on average-retard rather than foster innovation. When an innovation requires the migration of an innovation "as is" from one community to another (rather than the recombination and synthesis of elements from cognitively distant communities), network barriers-lack of social-cognitive ties among relevant communities-are likely relatively low given the continued decrease in access costs. ${ }^{278}$ Indeed, other innovation policy levers, such as constructing efficient knowledge infrastructures for searching patent documents worldwide, are better suited to foster the migration and repurposing of innovations from one community to another. ${ }^{279}$

It is in the doctrines of obviousness and utility, which I take up below, that judicial opinions assuming the free-flow of information across communities, and treating problem-finding and framing as exogenous, disincentivize the type of breakthrough innovation that requires deep and frequent interaction between groups with different cognitive repertoires.

\section{Obviousness}

A watershed decision in obviousness jurisprudence, $K S R v$. Teleflex, ${ }^{280}$ incorporates quite explicitly market failure analyses of innovation. In replacing the previous rigid test for obviousness with a flexible inquiry, the Court repeatedly emphasizes the importance of taking into account the impact of market forces on the direction of innovation and on the search strategies likely to be employed by innovators-seeking to exclude from patent protection those "predictable" inventions that are unlikely to result in market failures. ${ }^{281}$ In previous work, I have argued that the

276. Id. at 1478 (finding that the oil can dispenser was "inherently" capable of dispensing a few kernels of popcorn, as described by the Schreiber patent application).

277. Current novelty case law also raises the question: should the oil dispenser inventor benefit from the repurposing of his/her invention as a popcorn machine? The answer under current doctrine is yes: the popcorn machine literally infringes the Hertz patent, allowing the oil dispenser inventor to appropriate the social benefits of this repurposing. See Pennwalt Corp. v. Durand-Wayland, Inc., 833 F.2d 931, 949 (Fed. Cir. 1987) ("An infringement analysis, thus, requires that the courts look at each element of the claim, that is, proceed through the claim element-by-element, and look for correspondence in the allegedly infringing device.").

278. See supra Part II.B.

279. See infra Part V.A.

280. KSR Int'l Co. v. Teleflex Inc., 550 U.S. 398 (2007).

281. KSR Int'l Co. v. Teleflex Inc., 550 U.S. 398, 401 (2007). Christopher Cotropia has called this decision "Type I predictability," in which "the more predictable it is to use the prior art to make the invention, the more likely there was already a reason at the time of the invention for those of ordinary skill to make the necessary changes." Christopher A. 
Court's decision in $K S R$ can be interpreted as an invitation to incorporate not only economic but also social and psychological analysis into contextual determinations of non-obviousness. ${ }^{282}$ But regardless of whether one interprets $K S R$ as opening the door for a more grounded understanding of how scientific and technical research actually takes place, one thing is clear from the decision: the scope of prior art that a court can consider in assessing obviousness has expanded. ${ }^{283}$ In an oft-quoted passage, the Court emphasizes: "design incentives and other market forces can prompt variations of [a work available in one field of endeavor], either in the same field or in another." 284 The Court goes on to note that "familiar items may have obvious uses beyond their primary purposes, and a person of ordinary skill often will be able to fit the teachings of multiple patents together like pieces of a puzzle." 285 In other words, market pressures will incentivize a "person having ordinary skill in the art" (PHOSITA) to search broadly for information in its own community of practice and others. ${ }^{286}$ And both the Federal Circuit and academic commentators have interpreted the Court's decision as "direct[ing] [courts] to construe the scope of analogous art broadly." 287

The Court's expansive view of a PHOSITA's search strategies and access to information from multiple communities immediately lends itself to the following questions: how broadly would a putative inventor search for a solution? Should the sum of human knowledge be considered accessible to a PHOSITA when trying to solve a particular problem? And if not, what limits should be placed on the quantity of information available to a

Cotropia, Predictability and Nonobviousness in Patent Law After KSR, 20 MicH. Telecomm. \& Tech. L. Rev. 391, 391, 403 (2014).

282. Laura Pedraza-Fariña, Patent Law and the Sociology of Innovation, 2013 WIS. L. REV. 813, 825-26 (2013).

283. The expansion of the scope of the prior art inquiry is likely also a judicial response to the critique that, by failing to account for inventor creativity and lowered access costs, courts (and the Federal Circuit in particular) granted too many obvious patents that had the cumulative effect of impeding follow-on innovation. See, e.g., Michael Abramowicz \& John F. Duffy, The Inducement Standard of Patentability, 120 Y ALE L. J. 1590, 1597-98 (2011); Margo A. Bagley, Internet Business Model Patents: Obvious by Analogy, 7 Mich. Telecomm. \& Tech. L. Rev. 253, 258 (2001); Daralyn J. Durie \& Mark A. Lemley, A Realistic Approach to the Obviousness of Inventions, 50 WM. \& MARY L. Rev. 989, 990-91 (2008); Rebecca S. Eisenberg, Obvious to Whom? Evaluating Inventions from the Perspective of PHOSITA, 19 Berkeley TeCH. L. J. 885, 885 (2004); Brenda M. Simon, The Implications of Technological Advancement for Obviousness, 19 Мich. Telecomm. \& Tech. L. Rev. 331, 333-34 (2013); Ryan Whalen, Second-Order Obviousness: How Information and Communication Technologies Make Inventions More Obvious and Why the Law Should Care, 97 J. Pat. \& Trademark Off. Soc'y 597, 600 (2015).

284. KSR, 550 U.S. at 401.

285. Id. at 402 .

286. A "person having ordinary skill in the art" (PHOSITA) is a "hypothetical person," which has been likened to the "reasonable person" of tort law. Panduit Corp. v. Dennison Mfg. Co., 810 F.2d 1561, 1566 (Fed. Cir. 1987) (explaining that " "a person having ordinary skill in the art' [is] not unlike the 'reasonable man' and other ghosts in the law"); see also Jonathan J. Darrow, The Neglected Dimension of Patent Law's PHOSITA Standard, 23 HARV. J. L. \& TECH. 227, 227-28 (2009).

287. Wyers v. Master Lock Co., 616 F.3d 1231,1238 (Fed. Cir. 2010); see also Jacob S. Sherkow, Negativing Invention, 2011 B.Y.U. L. REv. 1091, 1118-20 (2011); Simon, supra note $283,339-40$. 
PHOSITA to make his/her invention? While making clear that the scope of the search was broad, the Court in KSR left this inquiry open for lower courts (and in particular the Federal Circuit) to elucidate. Patent law doctrine's response to this inquiry is the doctrine of analogous arts. ${ }^{288}$

The analogous arts doctrine in essence requires courts to, first, identify the "field of endeavor" for the invention at issue and, second, define the scope of "analogous" fields that an inventor in that field would be expected to access. ${ }^{289}$ Courts have formalized the analogous arts doctrine into a two-pronged test: a reference is "analogous" if (1) "it is from the same field of endeavor, regardless of the problem addressed" or (2) "if the reference is not within the field of the inventor's endeavor, . . . the reference still is reasonably pertinent to the particular problem with which the inventor is involved." 290 Courts, however, have struggled with applying this test in a predictable and consistent manner.

Regarding prong one, the Federal Circuit has recently clarified that the scope of a field of endeavor should be determined "by reference to explanations of the invention's subject matter in the patent application, including the embodiments, function, and structure of the claimed invention." 291 Applying this standard, one court held that "a person of ordinary skill, seeking to solve a problem of fastening a hose clamp, would reasonably be expected or motivated to look to fasteners for garments." 292 Yet another court held that the similarity in the "structure" of toothbrushes and hairbrushes dictated a finding that hairbrush and toothbrush design were part of the same field of endeavor. ${ }^{293}$

In a more recent and prominent case, Apple Inc. v. Samsung Electronics Co., Ltd., the Federal Circuit reasoned that Apple's "slide to unlock" \#721 patent and a prior art reference concerning touchscreen technology for wall-mounted devices were in the same field of endeavor because they "disclose[d] essentially the same structure-a touchscreen device with software that allows the user to slide his finger across the screen to

288. The analogous arts doctrine pre-dates $K S R v$. Teleflex, but it was hardly used by courts because the old non-obviousness test, the teaching-suggestion-motivation (TSM) test, narrowed the prior art to references that were already in communication with each other. See Pedraza-Fariña, supra note 282 , at $861-862$.

289. The two-prong test as most recently articulated by the Federal Circuit in Apple v. Samsung is:

A reference qualifies as analogous prior art if it is [a] "from the same field of endeavor, [determined by "the invention's subject matter in the patent application including the embodiments, function, and structure of the claimed invention"] regardless of the problem addressed"[;] or [b] "if the reference is not within the field of the inventor's endeavor, ... the reference still is reasonably pertinent to the particular problem with which the inventor is involved."

Apple Inc. v. Samsung Elecs. Co. Ltd., 816 F.3d 788, 802 (Fed. Cir. 2016) (quoting Wyers, 616 F.3d at 1237).

290. Id. (quoting Wyers, 616 F.3d at 1237) (internal quotation marks omitted).

291. In re Bigio, 381 F.3d 1320, 1325 (Fed. Cir. 2004).

292. In re Oetiker, 977 F.2d 1443, 1447 (Fed. Cir. 1992).

293. Bigio, 381 F.3d at 1327. 
change interface states." 294 On their end, Apple argued that there were two fields of inquiry at issue: one pertaining to cellular telephony and another to wall-mounted devices, such as home alarm systems. ${ }^{295}$

At this level of abstraction it is hard to know whether these cases were correctly decided, and indeed it is hard to reconcile courts' decisions in the Bigio and Oetiker cases. In Apple v. Samsung, it is quite possible that members of the two communities dealing with wall-mounted touchscreens and cellular telephony were in close communication with each other. It is equally as possible that they were not-at least not before Apple made its "slide to unlock" innovation. Indeed, if the history of the development of cellular telephones provides any guidance (which sociologists describe as the "uneasy" bringing together of radio and telephone engineers-two communities with "deep rooted" differences), ${ }^{296}$ the merger of touchscreen technology initially designed for home security systems with cellular telephones may indeed be a novel, breakthrough recombination bringing together two communities previously distant from each other. Common sense can tell us little about the organization of knowledge communities (and the interactions between them) in knowledge space. What we do know-as Parts II and III show-is that subcommunities of practice can be quite small and that popular, "common sense" conceptions of an interconnected world where interdisciplinarity is the norm are often incorrect. ${ }^{297}$

The analogous art inquiry does not end with a determination of what constitutes a relevant field of inquiry. Rather, prong two directs courts to ascertain "the nature of the problem to be solved" 298 and, from that vantage point, consider whether the prior art at issue "logically would have commended itself to an inventor's attention in considering his problem." 299 Notice how prong two places problem-solving squarely at the center of the courts' conception of innovative activity while assuming that problems to be solved are out there waiting-to-be solved. The next section explores and problematizes this assumption in patent doctrine.

\section{B. The Origin of Ideas Assumption in Patent Doctrine}

Part I described the view of innovation shared by market failure theories: problems to be solved, and ideas to solve them, are exogenous to

294. 816 F.3d at 803 .

295. Id. at 802-03.

296. Lester \& PiORE, supra note 178 , at 17 ("The companies that pioneered cellular [technology] typically came from either the radio or the telephone side of the business.... Each faced the major challenge of finding a partner who understood the other side of the technology and then learning to work intimately with that partner to create the new product. Not an easy task. The cultural differences between radio and telephone engineering were deep-rooted.").

297. See, e.g., Apple v. Samsung, 816 F.3d at 809 ("Considering the 'reality of the circumstances - in other words, common sense,' a skilled artisan would have considered Xrgomics to be within the scope of the art searched.").

298. KSR Int'l Co. v. Teleflex Inc., 550 U.S. 398, 414 (2007).

299. In re Clay, 966 F.2d 656, 659 (Fed. Cir. 1992). 
economic analyses of innovation. ${ }^{300}$ Court opinions take a similar view: innovation involves a "series of discrete problems and an associated series of decisions and choices about which of those problems to solve and how best to solve them." 301 This view of innovation is implicit in the Federal Circuit's obviousness and utility jurisprudence. As a consequence, patent law emphasizes (and thus incentivizes) problem-solving while deemphasizing (and thus disincentivizing) problem-finding and problemframing.

\section{Obviousness}

$K S R$ itself framed innovation entirely as an exercise in problem-solving. The Court emphasized that " $[\mathrm{u}]$ nder the correct analysis, any need or problem known in the [field of endeavor at the time of invention] and addressed by the patent can provide a reason for combining the elements in the manner claimed." 302 Similarly, secondary considerations-a list of factors courts use as proxies for assessing obviousness or non-obviousness of an invention-favor those innovators who provide a solution to longstanding problems but are silent regarding breakthrough problem-finding. ${ }^{303}$ More specifically, two secondary considerations, "long felt need" and "failure of others," have long been used to reward innovative problem-solving. ${ }^{304}$ Finally, prong two of the analogous arts doctrine, similarly focuses squarely on identifying relevant prior art by reference to "the particular problem with which the inventor is involved," 305 omitting any discussion on problem-finding. ${ }^{306}$ Because prong two of the analogous art doctrine has a large impact on the breadth of prior art considered by the court, the next paragraphs focus more in depth on how courts have carried out prong two analyses-identifying important biases against problem-framing and problem-finding.

How narrowly or broadly to frame the problem that the inventor was trying to solve is a key inquiry in analogous art jurisprudence. Patentees have an incentive to frame the problem narrowly to avoid prior art, while putative infringers have the opposite set of incentives. Faced with conflicting definitions of the "problem to be solved," courts have used an ad hoc approach, often relying on their own "common sense" to choose among possible problem framings. As Parts II and III show, however,

300. See supra Part I.B.

301. LeSTER \& PiORE, supra note 178, at 7.

302. KSR, 550 U.S. at 402.

303. See generally Natalie A. Thomas, Note, Secondary Considerations in Nonobviousness Analysis: The Use of Objective Indicia Following KSR v. Teleflex, 86 N.Y.U. L. REv. 2070, 2075 (2011).

304. See, e.g., C. Dylan Turner, In Cyclobenzaprine, an Objective Failure to Reach a Long-Felt Need in Secondary Considerations Jurisprudence, 13 Nw. J. TeCH. \& INTELL. PRop. 359, 362 (2015).

305. Apple Inc. v. Samsung Elecs. Co. Ltd., 816 F.3d 788, 802 (Fed. Cir. 2016).

306. Although "familiar items may have obvious uses beyond their primary purposes," $K S R, 550$ U.S. at 420 , a reference is only reasonably pertinent when it "logically would have commended itself to an inventor's attention in considering his problem," In re Clay, 966 F.2d 656, 659 (Fed. Cir. 1992). 
problem framing can be an important step in breakthrough innovationby taking it upon itself to "reframe" the problem in hindsight, courts are ignoring an important step in innovation. ${ }^{307}$

For example, in the Apple v. Samsung litigation, the Federal Circuit considered two different ways of framing the problem addressed by the patent. ${ }^{308}$ Apple framed the problem to be solved as "pocket dialing"the inadvertent activation of features in a portable device with a touchscreen. ${ }^{309}$ Because the prior art "describes a wall-mounted device to control home appliances like air-conditioning units and heaters," Apple argued, "a skilled artisan would not naturally turn to [the prior art] for solving the "pocket dialing' problem." 310 In contrast, Samsung framed the problem as one of designing user interfaces that employ touch-sensitive displays. $^{311}$ The Federal Circuit agreed with Samsung, concluding that "the problem faced by both the inventors of the \#721 patent and the authors of [the prior art reference] was similar-how to create intuitive, easy to understand interfaces for changing states on touchscreen devices. A skilled artisan would naturally turn to references like [prior art in touchscreen technology] to find solutions." 312 What the Federal Circuit's opinion overlooks is that understanding that both security system and cell phone designers faced similar design problems, and framing the problem of designing a user friendly interface for home entertainment and security systems as one of pocket dialing may, in itself, be an innovative contribution-particularly if these two communities were not in routine communication. ${ }^{313}$ Much like the solving of the Kadison-Singer problem, which required recognizing that the "sparsifying" problem facing computer scientists was the same as the "linear algebra matrices" problem in the several mathematics subcommunities, a key step in Apple's innovation may have been framing the "pocket dialing" problem as a problem present in home security systems. ${ }^{314}$

Not only does patent law privilege problem solving, but in some of its recent cases, it actively discounts problem-finding and problem-framing as an important source of innovative activity worth of reward. Courts

307. See Gregory N. Mandel, Patently Non-Obvious: Empirical Demonstration that the Hindsight Bias Renders Patent Decisions Irrational, 67 Оніо Sт. L. J. 1391 (2006); Gregory N. Mandel, Patently Non-Obvious II: Experimental Study on the Hindsight Issue Before the Supreme Court in KSR v. Teleflex, 9 YALE J. L. \& TeCH. 1 (2007).

308. Apple, 816 F.3d at 799-803.

309. Id. at 803 .

310. Id.

311. Id. at 802 .

312. Id. at 803 (emphasis added).

313. For example, in their three case studies of technological innovation in the cell phone, jean design, and medical device industries, Lester and Piore emphasize: "[I]ntegration turned out to be absolutely central in each of our case studies . . . . Without integration across the borders separating these different fields, there would have been no new products at all." Lester \& PiORE, supra note 178, at 14-15.

314. See Verizon Servs. Corp. v. Cox Fibernet Va., Inc., 602 F.3d 1325, 1338 (Fed. Cir. 2010) (finding that references relating to telephony and wireless communication were relevant to the Internet and network protocols because the "problem facing the inventors of the Network Patents was related to" the problem faced by the prior art references). 
often consider the problem the inventor was trying to solve as a giveneven if that problem was initially identified by the inventor him/herself and was, until then, unknown in the prior art. As Parts II and III discussed, this is problematic because for many breakthrough innovations, once a problem is correctly identified and framed, a solution can often reveal itself. ${ }^{315}$ In other words, it is often the finding and framing of the problem, not its solution, that is nonobvious.

The following case illustrates this point. The invention in Scientific Plastic Products v. Biotage concerned a low-cost, resealable cartridge that provides a tight seal under pressure for a chemical purification technique called "low-pressure liquid chromatography." 316 The primary issue in litigation was whether this invention was obvious in light of three references: the "Yamada" reference in the field of low-pressure liquid chromatography, and two references concerning the design of soda-pop bottle caps. ${ }^{317}$ The Yamada reference contained all the elements in the invention at issue, except for a special type of seal designed to prevent leaking under high pressure, which was present in the soda-pop bottle caps. ${ }^{318}$ In holding the invention obvious, the Federal Circuit reasoned that: "Here, the [soda-pop] references address the problem of providing a fluid tight seal at elevated pressures, between a container and a resealable cap. This is sufficiently close to the problem addressed by the claimed invention; substantial evidence supports the Board's finding that King and Strassheimer are available as prior art." 319 What the Federal Circuit overlooks, however, is that "the problem addressed by the claimed invention" was a design flaw that was identified by the patentees themselves. In essence, the court's opinion takes a problem identified and framed by the patentees as a given, and judges the obviousness of its solution in light of that problem. Judge Moore, dissenting, recognized this point. ${ }^{320}$ Judge Moore emphasized: "This statement [of a leakage problem], in the patents, is not a recognition of a known prior art problem that would have motivated one of skill in the art to want to modify the Yamada design. It was a problem identified, not in the prior art, but by these inventors. . . . These inventors identified a design problem, articulated it, and solved it." 321 The Supreme Court's 2015 denial of certiorari in this case is a missed opportunity to clarify the role of problem-finding and problem-framing in non-obviousness jurisprudence. ${ }^{322}$

315. See supra Part II.C \& Part III.

316. Sci. Plastic Prod., Inc. v. Biotage AB, 766 F.3d 1355, 1356 (Fed. Cir. 2014), cert. denied, 135 S. Ct. 2380 (2015).

317. Id. at 1358 .

318. Id. at 1360 .

319. Id.

320. Id. at 1362 (Moore, J., dissenting).

321. Id. at $1362-63$.

322. The question presented was "Whether an 'implicit' acknowledgment of a 'potential' problem or 'concern,' . . . is consistent with this Court's anti-hindsight jurisprudence requiring substantial evidence of a 'known problem' to provide a reason for combining references for an obviousness determination." Petition for Writ of Certiorari at i-ii, Sci. 


\section{Utility}

Patent law's emphasis on problem-solving is also evident in the third patentability doctrine: utility. ${ }^{323}$ The utility requirement, codified in section 101 of the patent act, requires that an invention have a "significant" and "immediate benefit to the public." 324 In other words, to be "useful," an invention must directly solve a specific public problem. Although utility is generally not a barrier to patentability for most inventions, the doctrine has been interpreted to bar patentability for chemicals and processes for making them, when no immediate benefit to the public from their use can be shown. ${ }^{325}$ In the leading utility case, Brenner $v$. Manson, the Supreme Court denied a patent on a process for producing a steroid that had no known use in humans, despite its similarity to other steroids that had been found to inhibit tumors in mice. ${ }^{326}$ In so doing, the Court emphasized that "a patent is not a hunting license. It is not a reward for the search, but compensation for its successful conclusion." 327 Following Brenner, the Federal Circuit has used this rationale to deny patents to chemical structures, chemical intermediaries, research tools, and, more broadly, to chemicals with no known use to the public at the time of the patent application-even if those chemicals have a clear use to specific research communities. ${ }^{328}$

Summarizing its view on utility, the Federal Circuit explained: "inventions do not meet the utility requirement if they are 'objects upon which scientific research could be performed with no assurance that anything useful will be discovered in the end." "329 The discovery of "objects upon which scientific research could be performed," 330 however, amounts to problem-finding and problem-framing. In some ways, the reasoning of the Court is exactly backwards: discovering "objects upon which scientific research could be performed" 331 is often in itself more useful to scientific advances (and ultimately to the public) than discovering a single specific use for an existing chemical (an activity that is patentable). ${ }^{332}$ This is because, as the case studies in Part III demonstrate, finding a new problem

Plastic Prods., Inc. v. Biotage AB, 766 F.3d 1355 (Fed. Cir. 2014) (No. 14-1186), 2015 WL 1384354 , at $* 1$.

323. See, e.g., Fromer, supra note 118, at 1444.

324. In re Fisher, 421 F.3d 1365, 1371 (Fed. Cir. 2005) (citing Nelson v. Bowler, 626 F.2d 853, 856 (C.C.P.A. 1980)) (emphasis omitted).

325. See Sean B. Seymore, Making Patents Useful, 98 Minn. L. Rev. 1046, 1060-66 (2014).

326. Brenner v. Manson, 383 U.S. 519, 521-22, 535 (1966).

327. Id. at 536 .

328. Seymore, supra note 325.

329. In re '318 Patent Infringement Litig., 583 F.3d 1317, 1324 (Fed. Cir. 2009) (citing Fisher, 421 F.3d at 1373).

330. Id.

331. Id.

332. See, e.g., Rebecca S. Eisenberg, J.D., The Problem of New Uses, 5 Yale J. Health Pol'y, L. \& Ethics 717 (2005); Benjamin Roin, Solving the Problem of New Uses (Oct. 13, 2013) (unpublished manuscript) (on file with Harvard Digital Access to Scholarship), https://dash.harvard.edu/handle/1/11189865 [https://perma.cc/ZAS2-93ZK]. 
and framing it in a way that it can be successfully tackled by researchers can be generative of many new insights and new solutions that indirectly benefit the public. Indeed, this is the view that the Federal Circuit adopted prior to Brenner, in its "inherent utility" doctrine, which recognized that "pure research often has an intrinsic utility despite no immediate use for the fruits of the research." 333 By ignoring the importance of problem-finding and problem-framing to innovation, the utility doctrine as applied to chemical and pharmaceutical innovation, as Sean Seymore has remarked, "now has nothing to do with the invention's inherent usefulness to a PHOSITA, ability to advance scientific knowledge, or potential to indirectly benefit the public." 334

\section{Comparison with Psychological Approaches}

The critique articulated here departs from previous analyses of patent jurisprudence based on psychological understandings of creativity. Jeanne Fromer, for example, has argued that patent law appropriately focuses on problem solving, and not on problem finding. ${ }^{335}$ Fromer justifies this focus on problem solving with three interrelated arguments. First, "[t]he psychological literature shows that ... [o]ur culture cares about how well an invention grounded in scientific or engineering principles solves an identified problem rather than the fact that someone figured out that there was a problem in the first place." 336 Second, engineers themselves "believe that having solutions, developing valuable answers, and being analytical are essential to scientific creativity." 337 Third, although basic research scientists have long-emphasized the importance of finding and framing a problem, the same is not the case for the field of applied sciences-which is the proper field of reference for patent law. 338

While our culture and some scientists themselves may indeed value problem solving over problem finding and framing, this likely reflects biases and incorrect perceptions about the origin of innovation. For example, one sociological study of innovation in the cellular telephone, designer jeans, and medical devices industries found that the engineers and managers involved in product development in these areas displayed a fundamental bias towards "analytical problem-solving" "that grew out of [their] training [that] ... reflected an analytical approach to the overall task of product development and to the roles of managers and engineers in this process." 339 This study also concluded, however, that problemfinding and framing was a crucial, yet underappreciated, element in the

333. Salim A. Hasan, A Call for Reconsideration of the Strict Utility Standard in Chemical Patent Practice, 9 High Tech. L. J. 245, 253-54 (1994) (citing In re Nelson, 280 F.2d 172, 180-81 (C.C.P.A. 1960)).

334. Seymore, supra note 325 , at 1066.

335. Fromer, supra note 118, at 1444, 1489.

336. Fromer, supra note 118, at 1469.

337. Fromer, supra note 118 , at 1470.

338. Fromer, supra note 118, at 1502-03.

339. Lester \& Piore, supra note 178, at 34. 
development of cellular telephones, designer jeans, and medical devices. ${ }^{340}$ Moreover, a focus on problem finding and framing does not preclude a concurrent focus on problem solving. Indeed valuing (and incentivizing) problem-finding and problem-framing is likely to lead to more problems being solved: the rate-limiting step in many important innovations is the re-framing of existing problems so that they are amenable to solution by tools present in other communities. Finally, the science/ technology distinction, while valid, is in many ways artificial. ${ }^{341}$ The applied scientists who work in product-development companies have the same training and many of the same community affiliations as those in universities. ${ }^{342}$ Indeed university education in specific subdisciplines socializes engineers into communities of practice-and the bias towards problem-solving emerges in part from the nature of that education. ${ }^{343}$ Most importantly, sociological studies, including the Oncofertility case study described in Part III, find that problem-finding and problem-framing are also crucial in product development. ${ }^{344}$ Indeed, many of the problems found by the Oncofertility consortium have led to patentable innovations, such as a biomesh for growing eggs in vitro. ${ }^{345}$

\section{Correcting Mistaken Assumptions}

Three points emerge from the analysis in the previous two sections: first, the free flow of information assumption has taken hold in patent law doctrine, with courts often assuming that, as access costs have declined, information will flow freely across subcommunities of practice. Second, the Federal Circuit has provided no principled way to define what constitutes a field of endeavor or to "predict how narrowly or broadly a court will define the relevant field of the inventor's endeavor or the problem to be solved." 346 Third, courts have failed to appreciate the importance of problem-finding and problem-framing in innovation.

Incorporating social network research to patentability analysis both challenges this uniformly expansive view of the prior art and gives lawmakers and courts tools to define the relevant field (or community) of invention and its interactions with other neighboring fields (or communities). Network theory can provide tools and metrics that can turn the subjective analogous arts inquiry into a more objective one.

Social network researchers have long used citations in academic papers to construct networks of communities of academic researchers and to

340. Lester \& Piore, supra note 178 , at 8.

341. I have made this point elsewhere. See Pedraza-Fariña, supra note 282, at 854-56.

342. Pedraza-Fariña, supra note 282, at 855-856.

343. Lester \& Piore, supra note 178, at 154-55.

344. See supra Part II.

345. See, e.g., Hydrogel Compositions, U.S. Patent Application No. PCT/US2008/ 053287 (filed Feb. 7, 2008), Publication No. WO 2008098109, at A2 (published Aug. 14, 2008), https://google.com/patents/WO2008098109A2?cl=en [https://perma.cc/P457-BZUH].

346. Bagley, supra note 283, at 270; see also Sherkow, supra note 287, at 1114; Simon, supra note 283 , at 354 . 
identify structural holes among them. ${ }^{347}$ Researchers are beginning to employ the same tools for patent citations and to use patent citation networks to reconstruct the relevant communities of practice (or technological fields) and their change over time. ${ }^{348}$ Social network analysis can be useful to better define technology subclasses used by the PTO and international bodies to classify patent applications and assign them to particular Art Units. ${ }^{349}$ But more narrowly for the purpose of this Article, the PTO can use its existing technological subclasses-which it uses to classify patent applications ${ }^{350}$ — to ask the question: have these technology subclasses been combined in a patent application (by another inventor) before? If so, is the combination rare or common? A rare or novel combination suggests the presence of a structural hole between those technology classes and counsels against considering information from those two domains as analogous art. Rather than rely on expert testimony alone, patent applicants before the PTO (or litigants before a court) could also introduce evidence that a particular patent employed a rare combination of technological subclasses as evidence of non-obviousness. Conversely, a frequent combination of technological subclasses indicates those communities are in close contact and that the information pertaining to those classes is likely analogous prior art. Indeed, researchers Lee Fleming, Santiago Mingo, and David Chen have used this methodology to track the emergence of new pairs of patent subclasses. ${ }^{351}$

Giving problem-finding and problem-framing its due in the innovative process will require changes in courts' articulation of the analogous arts and utility doctrines. First, problems found or re-framed by the inventor should not be used as a starting point in the obviousness analysis. If there was no known "problem" to be solved, prong 2 of the analogous art inquiry is simply inapposite. ${ }^{352}$ Second, social network theory shows that the problems that are harder to find (and more likely to lead to breakthrough innovation) are those that sit at the intersection of two or more communities of practice that are separated by a structural hole. For example, the problem of how to provide fertility options to cancer patients, as

347. See, e.g., Martin Rosvall \& Carl T. Bergstrom, Maps of Random Walks on Complex Networks Reveal Community Structure, 105 PNAS 1118 (2007), http://www.pnas.org/ content/105/4/1118.full.pdf [https://perma.cc/756N-FY7B].

348. See, e.g., Peter Erdi et al., Prediction of Emerging Technologies Based on Analysis of the U.S. Patent Citation Network, 95 Scientometrics 225 (2013); Ryan Whalen, Knowledge Recombination, Diffusion and Research Team Composition: UnderSTANDING 21st CENTURY InNOvation (unpublished dissertation, Northwestern University) (dissertation on file with author).

349. A description of the international patent classification system can be found here: International Patent Classification (IPC), WORLd InTell. Prop. Org., http://www.wipo .int/classifications/ipc/en [https://perma.cc/7XEM-LGZ3]; The U.S. Patent classification system is described here: U.S. Classes by Number with Title Menu, U.S. PAT. \& TradeMARK OFF. (USPTO), https://www.uspto.gov/web/patents/classification/selectnumwithtitle .htm [https://perma.cc/YW46-7GTG].

350. USPTO, supra note 349.

351. Fleming, supra note 138, at 444.

352. Federal Circuit caselaw is conflicting on this point-leading to a petition for certiorari in Scientific Plastic Products v. Biotage. Petition for Writ of Certiorari, supra note 322. 
well as the narrower research problem of how to explain the difference between mouse and monkey models of egg development, emerged at the intersection of oncology and two subcommunities of reproductive endocrinologists. Thus, a problem found by a patentee whose patent includes a novel combination of technological subclasses constitutes strong indicia of non-obviousness - one that should be taken into account alongside other more traditional indicia of non-obviousness such as "long-felt need" and "failure of others." 353

The case for finding utility when the "problem found or framed" is directly useful to the scientific community but only indirectly useful to the public is complicated by the concern, articulated by the Court in Brenner, that rewarding problem-finding alone will "confer power to block off whole areas of scientific development, without compensating benefit to the public." 354 In other words, requiring an invention to have an immediate public benefit is thought to guard against excessive patent scope. Concerns about patent scope are very important. Research described in Parts II and III demonstrates how problem finding at the intersection of multiple fields can give rise to entire new areas of research, as was the case with the creation of the field of Oncofertility. Giving inventors a patent for finding and framing a valuable problem therefore has the very real potential of "block[ing] off whole areas of scientific development." 355 There are, however, other doctrines better suited to the task of policing patent scope than utility-namely, patentable subject matter, enablement, and written description. ${ }^{356}$ After all, the inventor of a new chemical compound need only find a single plausible use for a compound to obtain a patent that can then block the practice of any other future uses discovered by a third party, even if those future uses are more socially beneficial than the initial use discovered by the patentee. The Federal Circuit's previous "inherent utility" doctrine, articulated in Nelson, ${ }^{357}$ struck the right balance by recognizing that an invention does not lack utility if it provides an immediate benefit to the research community, despite its indirect benefit to the public.

\section{IMPLICATIONS FOR INNOVATION THEORY}

Understanding when and why information does not flow freely across communities of practice, and how creative ideas emerge, has implications for innovation policy beyond patent law doctrine. By identifying specific social barriers to information flow and recombination, the taxonomy of social network failures developed in Part III serves as a guide to design targeted cures and to evaluate their effectiveness. Market failure analyses of innovation have framed academic debates on the merits and demerits

353. Turner, supra note 304 , at 362.

354. Brenner v. Manson, 383 U.S. 519, 534 (1966).

355. See id.

356. See 35 U.S.C. $\S \S 101,112$ (a) (2012); see also Seymore, supra note 325, at 1083.

357. In re Nelson, 280 F.2d 172, 184-85 (C.C.P.A. 1960). 
of different innovation levers (for example, patents, grants, prizes) by providing an organizing question: given our understanding of why markets fail to optimally induce innovation, which type of intervention can best cure market failures? ${ }^{358}$ Likewise, social network analysis invites comparison of these innovation levers, by asking: given our understanding of why structural folds fail to form, which type of intervention can best cure social network failures?

Although addressing (and correcting) hidden assumptions behind patent law doctrine is necessary to bring patent law in line with the realities of scientific and technical research, in the final analysis, patent law as an innovation tool may not be the most efficient policy to address social network failures. An answer to this question requires viewing innovation through a broader lens that includes the role of private ordering, government grants, prizes, and taxes. The scope of this question is necessarily broad, and its full answer is beyond the scope of this Article. The remainder of this Article, however, begins this analysis by outlining how understanding the three barriers to information flow and recombination described in Part III-(1) lack of social-cognitive ties, (2) cognitive distance, and (3) different (clashing) evaluative frames-can be harnessed to design policy interventions. This Part also sets out a research agenda with social network failures as its guide.

\section{A. Building KNowledge Infrastructures}

As Part III explained, this first social barrier to information flow and recombination stems directly from Burt's studies on structural holes in the information space: how a community member searches for information and prioritizes found information is deeply informed by whom she knows (a social tie) and what those connections know (a cognitive tie). ${ }^{359}$ Curing the lack of social-cognitive ties across communities of practice requires more than simply making information "free" or "open." For example, recall that research results from the three different communities involved in tobacco research (and described in the case study in Part III) were in the public domain for more than a decade before they were productively recombined.

The National Cancer Institute addressed the lack of social-cognitive ties across communities involved in tobacco research through the creation of a knowledge infrastructure that made research from all NCI-funded communities working on tobacco easily available and searchable. ${ }^{360}$ The key goal of a knowledge infrastructure is to serve as a repository of information that is curated and organized in particular ways that allow previously unseen connections to be made across communities working on

358. See supra Part I.

359. See supra Part II.A.

360. See, e.g., Leischow et al., supra note 201, at S199-S200 (describing NCI's knowledge infrastructure for tobacco research). 
related topics and/or problems. ${ }^{361}$ Knowledge infrastructures can enable both raw and published data sharing, as well as the sharing of knowhow. ${ }^{362}$ They can also directly facilitate personal connections across communities of practice. ${ }^{363}$ Knowledge infrastructures could also help inventors and the PTO search patent disclosures and other documents-and identify relevant prior art-more effectively. ${ }^{364}$

How to build effective knowledge infrastructures, either through governmental initiatives such as those by the National Cancer Institute or through private funding at universities, research centers, or private firms, and how these infrastructures interact with patent law and policy, should be an important area of future research in intellectual property law and policy. 365

Creating knowledge infrastructures is particularly effective in remedying social network failures when the only social barrier dividing communities is lack of socio-cognitive ties. When communities can understand and interpret each other's research, and when they share evaluative frames, knowledge infrastructures are a very powerful tool in solving social network problems. But in the absence of deep interaction between communities, knowledge infrastructures won't help create a creole at the intersection of communities to find and solve shared problems. To the contrary, one important concern is that knowledge infrastructures,

361. For example, the Tobacco Informatics Grid (TobIG) uses "state-of-the-science information technology and networking software to link tobacco data, researchers, and resources (e.g., citation indexes, data mining, and visualization software)." Leischow et al., supra note 201, at S199. Another knowledge infrastructure in nanotechnology, "was created to "accelerate the vetting of new knowledge and to enable effective data utilization." NSI: Nanotechnology Knowledge Infrastructure (NKI)_Enabling National Leadership in Sustainable Design, U.S. Nat'L Nanotechnology Initiative, http://www.nano.gov/NKIPortal [https://perma.cc/4AK2-MRBM] (last visited Mar. 25, 2017). The Oncofertility Consortium also developed a knowledge infrastructure, the "National Physician's Cooperative," to share research tools and protocols for fertility preservation techniques among consortium members. Pedraza-Fariña, supra note 233, at 1; see also EDWARDS ET al., Knowledge Infrastructures: Intellectual Frameworks and Research Challenges 23-24 (2013), http://knowledgeinfrastructures.org [https://perma.cc/G4MQFU3Q]; Michael J. Madison, Knowledge Curation, 86 Notre Dame L. Rev. 957 (2011) (describing the importance of considering the role of knowledge curation in fostering innovation).

362. See, e.g., Leischow et al., supra note 201, at S199-S200; Pedraza-Fariña, supra note 233, at 15 (describing raw data, published data, and know-how sharing in the National Physicians Cooperative).

363. See, e.g., Leischow et al., supra note 201, at S196 (advocating a "network-centric approach [to public health] that encourages relationship-building among and between individuals and organizations across traditional disciplines and fields in order to achieve relevant goals and objectives").

364. See, e.g., Prithwiraj Choudhury \& Tarun Khanna, Ex-ante Information Provision and Innovation: Natural Experiment of Herbal Patent Prior Art Adoption at the USPTO and EPO 3 (Harvard Bus. Sch. Working Paper No. 14-079, 2015), http://www.hbs.edu/ faculty/Publication\%20Files/14-079_2fb4af35-dc4e-467d-8f25-512398286391.pdf [https://per ma.cc/AU4Z-T4JW] (arguing that the codification of prior art in easy-to-search databases improves decision-making at the PTO).

365. Brett Frischmann has written persuasively about the importance of recognizing the indirect-but foundational-benefits of infrastructure to innovation. See, e.g., BRETT M. Frischmann, Infrastructure: The Social Value of Shared Resources xv, 253 (2012). 
through their "commodification" of data (i.e. "the presentation of datasets as complete, interchangeable products in readily exchanged formats"366), "may encourage misinterpretation, over reliance on weak or suspect data sources, and 'data arbitrage' based more on availability than on quality" 367 across distant communities of practice. This is because what constitutes a "unit" of data is often not commensurable across communities of practice, which have different ways of valuing, collecting, and analyzing data. In other words, the meaning of data depends on understanding how, where, when, and by whom they were created. ${ }^{368}$

What additional tools, then, could be harnessed to cure "cognitive distances" and "different (clashing) evaluative frames"? The following two sections begin this analysis.

\section{B. Building Teams with Overlapping Membership Structures}

As research on structural folds makes clear, bridging large cognitive distances-often a prerequisite for breakthrough innovation-requires the frequent, face-to-face interaction of members from the relevant distant communities. ${ }^{369}$ Indeed, when communities' cognitive distances are large-as was the case with the mathematics and computer science communities involved in solving the Kadison-Singer problem-deep interaction is often a precondition for the creation of useful knowledge infrastructures that span these communities. This is because before useful data can be collated, curated, and coded, communities must develop a shared understanding (a creole) regarding what constitutes data worth coding and storing, how to collect relevant data, and how to classify it. ${ }^{370}$ The policy question for remedying this second type of social network failure then becomes: how can policy tools be leveraged to (1) identify (and frame) complex problems whose solution requires expertise from multi-

366. EDWARDS ET AL., supra note 361, at 7.

367. EDWARDS ET AL., supra note 361, at 7.

368. EdwARdS ET AL., supra note 361, at 7 (citing Sean Bechhofer et al., Why Linked Data Is Not Enough for Scientists, in 2010 SiXTH IEEE InTERNATIONAL CONFERENCE on E-SCIEnCE 300 (2010); Matt Burton \& Steven J. Jackson, Constancy and Change in Scientific Collaboration: Coherence and Integrity in Long-Term Ecological Data Production, in 2012 45th Hawait International Conference on System Science 353 (2012); C. Bowker et Al., "RAw DatA" Is An Oxymoron (Lisa Gitelman ed., 2013); David Ribes \& Steven J. Jackson, Data Bite Man: The Work of Sustaining Long-Term Data Collection, in "Raw DatA" is An Oxymoron (Lisa Gitelman ed., 2013)); see also Alaina G. Kanfer et al., Modeling Distributed Knowledge Processes in Next Generation Multidisciplinary Alliances, in Information Systems Frontiers 317 (2000); Ann Zimmerman, A Socio-Technical Framework for Cyberinfrastructure Design, in e-Social SCience Conference (Oct. 7-9, 2007), http://citeseerx.ist.psu.edu/viewdoc/down load?doi=10.1.1.108.2422\&rep=rep1\&type=pdf (citing K.A. Lawrence Walking the Tightrope: The Balancing Acts of a Large e-Research Project, 15 COMPUTER SuPPORTED CoOPERATIVE WORK 385 (2006); Charlotte P. Lee et al., The Human Infrastructure of Cyberinfrastructure, in Proceedings of the Conference on Computer Supported Cooperative Work (2006); David Ribes \& Thomas A. Finholt, Tensions Across the Scales: Planning Infrastructure for the Long-Term, in ProceEdings of THE INTERNAtional ACM SigGroup Conference on Supporting Group Work (2007)).

369. See supra Part II.B.

370. Supra Part II.B. 
ple communities; and (2) foster the sustained, deep interaction between those communities to address those problems?

In the case of the Kadison-Singer problem, the key to its solution was understanding that it could be framed as equivalent to a problem in computer science, for which computer scientists had developed unique tools. As Part III explains, solving the Kadison-Singer problem also brought together groups of computer scientists and mathematicians to develop a shared language to address its myriad implications-in effect, seeking to create a structural fold where new recombinations can take place. For example, mathematicians and computer scientists have organized joint conferences and Kadison-Singer tutorials. ${ }^{371}$ This is, in effect, a "private ordering" response to the problem of creating structural folds. It is too early to tell whether these novel teams of computer scientists and mathematicians working on the implications of the solution of the KadisonSinger problem will develop the kind of sustained, deep interaction necessary for cross-cutting innovation. But what research on structural folds has taught us is that any initiative seeking to foster the development of boundary-crossing teams should ensure that at least some of its participants have overlapping memberships in multiple communities, as well as pre-existing social relationships across community boundaries. ${ }^{372}$ Additional research should seek to further elucidate the characteristics of successful boundary-crossing teams, as well as how private ordering solutions can interact with policy initiatives such as grants, prizes, or patents, to both assemble and maintain such successful teams. ${ }^{373}$

This private-ordering solution, however, leaves unexplored how to foster the identification and framing of complex problems at the intersection of multiple communities in the first place. Restructuring the obviousness and utility doctrines to value problem-finding and problem-framing is one partial solution, as Part IV discusses. ${ }^{374}$ But more direct interventions are also possible. For example, government grants or prizes can be structured to incentivize the identification of problems whose solution requires the combined expertise from multiple disciplines and subdisciplines. This is precisely how the NIH Roadmap grant that funded the Oncofertility consortium and eight others was structured. ${ }^{375}$ It bears noting, however, that the Interdisciplinary Consortia grant was unusual, as most grants are currently structured along disciplinary lines. ${ }^{376}$ For example, the NIH, the

371. See, e.g., Klarreich, supra note 15.

372. See supra Parts II.B \& II.C.

373. There is a growing group of intellectual property scholars that has begun to tackle these questions. See, e.g., Katherine J. Strandburg, Derogatory to Professional Character? The Evolution of Physician Anti-Patenting Norms, in Creativity without Law: Challenging the Assumptions of Intellectual Property (Kate Darling \& Aaron Perzanowski eds., 2017); Dan L. Burk, Patent Silences, 69 VAND. L. Rev. 1603 (2016) (arguing that patents can serve as "boundary objects" to facilitate interaction across disciplines); Pedraza-Fariña, supra note 233 (describing how a successful boundary-crossing team deploys patent law, grants, and informal norms in data-sharing).

374. See supra Part IV.

375. Zerhouni, supra note 234.

376. Zerhouni, supra note 234. 
nation's largest grant-making organization, gives individual Institutes grant-making authority over their specialized field and typically assembles grant review panels with relatively narrow expertise. ${ }^{377}$ Legal scholarship on intellectual property and innovation law more broadly has paid comparatively little attention to how to design grants and prizes to foster innovation, and how grant-making interacts with other innovation policies-and patents in particular.

When the barrier to assembling boundary-crossing teams is simply the cognitive distance between two communities-for example, in the Kadison-Singer problem, the inability of mathematician/computer science teams to understand each other's disciplinary tools and ways of tackling problems - identifying and framing the common problem and providing a space and platform for sustained interaction is likely sufficient to cure this social network failure. But the final social network failure identified in this Article-different (or clashing) evaluative frames - presents an additional set of problems. Communities with different, and often clashing, frames to evaluate the worth of research projects, tools and results, may be unwilling to engage in shared dialogue. The next section analyzes how this third type of social network failure can be remedied.

\section{Emphasizing Problem-Based vs. Discipline-based Funding}

As the Oncofertility case study in Part III illustrates, the different evaluative frames used by oncologists and endocrinologists led to different research priorities and practice styles that kept the two communities from working together on addressing the impact of cancer treatment on fertility. ${ }^{378}$ As the case study also emphasizes, an important barrier to collaboration was the educational, professional, and funding structures of the two communities. At the educational level, the training of oncology and endocrinology professionals reinforced their divergent frames (focused on improving survival rates for the former, and on understanding infertility in "otherwise healthy" patient populations for the latter). ${ }^{379}$ At a professional level, treatment guidelines for oncologists and endocrinologists sidelined the issue of fertility and cancer treatments. ${ }^{380}$ Finally, at a funding and evaluation level, both university departments and grant review boards typically emphasize knowledge and expert use of the tools of their particular discipline to address problems considered salient by that discipline-often discouraging interdisciplinary projects. 381

What all of these social barriers have in common is a discipline-basedas opposed to a problem-based - approach to training, funding and evalu-

377. See Nat'l Insts. of Health, NiH Peer Review: Grants and Cooperative AGREEMENTs, https://grants.nih.gov/grants/peerreview22713webv2.pdf [https://perma.cc/ UAA9-4U73].

378. See supra Part III.C

379. Interview with Oncofertility Consortium researchers, clinicians and administrators (Mar. 10, 2015).

380. Id.

381. Id. 
ation. The NIH Interdisciplinary Consortia grant presents a useful counterexample of a successful problem-based approach to funding. Instead of asking for proposals that fit within the disciplinary purview of a particular NIH institute, the Consortia grant explicitly asked researchers to identify problems that required joint expertise, both at the level of the scientists involved and of the funding institutes. ${ }^{382}$ A problem-based approach to project evaluation could also diminish disciplinary resistance to considering alternative research tools. For example, some conferences have instituted a novel multi-methodological review process for boundary-crossing projects. ${ }^{383}$ And in the case of patent law, a reframed obviousness and utility inquiry that recognizes the existence of social network failures, and rewards those who successfully breach them, would serve the same goal.

\begin{tabular}{|l|l|l|}
\multicolumn{1}{|c}{ Social Network Failure } & \multicolumn{1}{c}{ Example } \\
Lack of social-cognitive ties & $\begin{array}{l}\text { Tobacco } \\
\text { Research }\end{array}$ & $\begin{array}{l}\text { Build knowledge } \\
\text { infrastructure (e.g. Tobacco } \\
\text { Informatics Grid (TobIG); } \\
\text { structured patent prior art } \\
\text { search tools) }\end{array}$ \\
\hline Cognitive distance & $\begin{array}{l}\text { Kadison-Singer } \\
\text { Problem }\end{array}$ & $\begin{array}{l}\text { Build teams with overlapping } \\
\text { membership structures } \\
\text { (through private initiatives, } \\
\text { special grants and prizes, } \\
\text { reframed obviousness, and } \\
\text { utility inquiry) }\end{array}$ \\
\hline $\begin{array}{l}\text { Different (clashing) evaluative } \\
\text { frames }\end{array}$ & Oncofertility & $\begin{array}{l}\text { Emphasize problem-based (vs. } \\
\text { discipline-based) funding and } \\
\text { evaluation mechanisms } \\
\text { (through multidisciplinary } \\
\text { review and funding } \\
\text { mechanisms, reframed } \\
\text { obviousness and utility } \\
\text { inquiry) }\end{array}$ \\
\hline
\end{tabular}

Figure 6: Designing Innovation Policy to Cure Social Network Failures

\section{CONCLUSION}

Relying on original case studies of innovation and theoretical and empirical research in the sociology of networks, this Article identified and characterized a novel set of innovation failures tied to the social structure of knowledge-making that underlies market transactions: social network innovation failures. Understanding how social network innovation fail-

382. See Zerhouni, supra note 234.

383. See, e.g., Nagib Callaos, A Multi-Methodological Review Process for Multi-Disciplinary Conferences, 8Th International Multi-Conference on Complexity, InformatICS \& CYBERNETICS: IMCIC 2017 (Mar. 21-24, 2017), http://www.iiis-spring17.org/imcic/ Website/MMRPfMDC.asp?vc=26 [https://perma.cc/L4QC-F4VE]. 
ures emerge and are maintained is an important complement to traditional market failure analyses of innovation, which have long guided policy interventions - including in patent law. Indeed, the three specific types of social network failures identified in this Article: (1) lack of social-cognitive ties; (2) cognitive distance; and (3) different (clashing) evaluative frames, recommend the reorganization of innovation policy to prioritize the building of knowledge infrastructures and the restructuring of research funding from a discipline-based to a problem-based model. Viewing innovation from the perspective of social network failures thus provides a complementary toolkit with which to both design and analyze innovation policies.

A second contribution of this Article is to expose and challenge two assumptions made in market failure models of innovation, and reflected in patent law doctrine: the free-flow of information, and the treatment of ideas as exogenous to economic analysis. Social network research shows that the rate-limiting step in breakthrough innovation, new problem-finding and problem-framing, happens at structural folds: areas poised with "generative tension" where cognitively-distant communities interact. Structural folds, however, are fragile and rare: idea exchange at structural folds is often threatened by structural holes in the information space (i.e. social barriers to information flow). The Supreme Court and the Federal Circuit, however, have failed to appreciate both the important difficulties in information flow across some subcommunities of practice, and the crucial role played by problem-finding and problem-framing in innovation. Thus, an important direct pay-off of a social network failure framework is to offer specific doctrinal changes to obviousness and utility jurisprudence to better align patent law doctrine with the sociological realities of scientific and technological research.

Finally, patent law not only reflects understandings about how scientific and technical research is organized on the ground, but also has an (expected) feedback effect on the pace and direction of innovation itself. Therefore, a key question that remains to be fully explored is: how does the current structure of patent law influence the exchange and recombination of ideas across structural holes? This Article has emphasized the likely negative effect of current obviousness and utility doctrines, which discount problem-finding and problem-framing, on boundary-crossing innovation. But further research is needed to understand how the social barriers to information flow and recombination identified in this Article interact both with other informal social norms of research and with formal structures designed to incentivize innovation such as patents, grants, and prizes. ${ }^{384}$

384. Legal scholars have begun to tackle these questions. See, e.g., Burk, supra note 373 (arguing that patents can serve as "boundary objects" that coordinate research across innovator communities); Strandburg, supra note 373, at 81 (documenting how physician userinnovators use patents as a "boundary spanning tool" to coordinate joint innovation with commercial firms); Pedraza-Fariña, supra note 233 (analyzing how the Oncofertility consortium relied on informal norms and formal incentives such as grants to structure collabo- 
ration across disciplines); Anthony J. Casey \& Andres Sawicki, The Problem of Creative Collaboration, 58 WM. \& MARY L. REv. (forthcoming 2017). Scholars writing mainly in contract law have also begun to explore these questions from a different but complementary perspective. See, e.g., Ronald J. Gilson, Charles F. Sabel \& Robert E. Scott, Braiding: The Interaction of Formal and Informal Contracting in Theory, Practice, and Doctrine, 110 Colum. L. Rev. 1377 (2010); Matthew Jennejohn, The Private Order of Innovation Networks, 68 StAn. L. Rev. 281 (2016). Other scholars have argued that patent rights can harm self-sustaining information sharing commons-such as open-source and crowdsourcing models-by creating patent thickets that increase transaction costs and by crowding out intrinsic motivations to share data openly. See, e.g., Lisa S. Vertinsky, Making Room for Cooperative Innovation, 41 FLA. STATE L. REv. 1067, 1070 (2014) (arguing that patents can increase "incentives for group members to defect from the group" by weakening "intrinsic motivations and the related norms of trust and sharing that cooperative systems rely upon.”); Clark D. Asay, A Case for the Public Domain, 74 Oнго Sт. L.J. 753 (2013); Jason Schultz \& Jennifer M. Urban, Protecting Open Innovation: The Defensive Patent License as a New Approach to Patent Threats, Transaction Costs, and Tactical Disarmament, 26 Harv. J.L. Tech. 1 (2012); Greg R. Vetter, A Public Domain Approach to Free and Open Source Software?, 75 Ohio St. L.J. Furthermore (2014). 